Supporting Information

\title{
Synthesis of Allenes by Catalytic Coupling of Propargyl Carbonates with Aryl Iodides in the Presence of Diboron Species
}

\author{
Yuzhu Yang and Kálmán J. Szabó* \\ Department of Organic Chemistry, Arrhenius Laboratory, Stockholm University, SE-10691 \\ Stockholm, Sweden \\ E-mail: kalman@organ.su.se, web: http://www.organ.su.se/ks
}

\section{Contents:}

${ }^{1} \mathrm{H}$ and ${ }^{13} \mathrm{C}$ NMR Spectra for $7 \mathbf{a}-7 \mathbf{o}$

S2-S31 

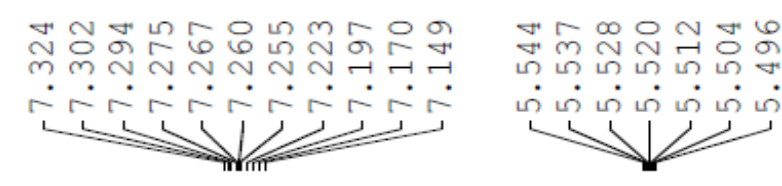

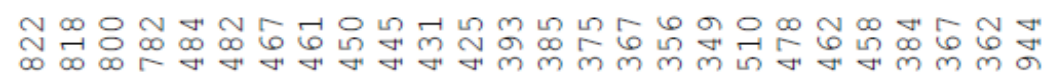
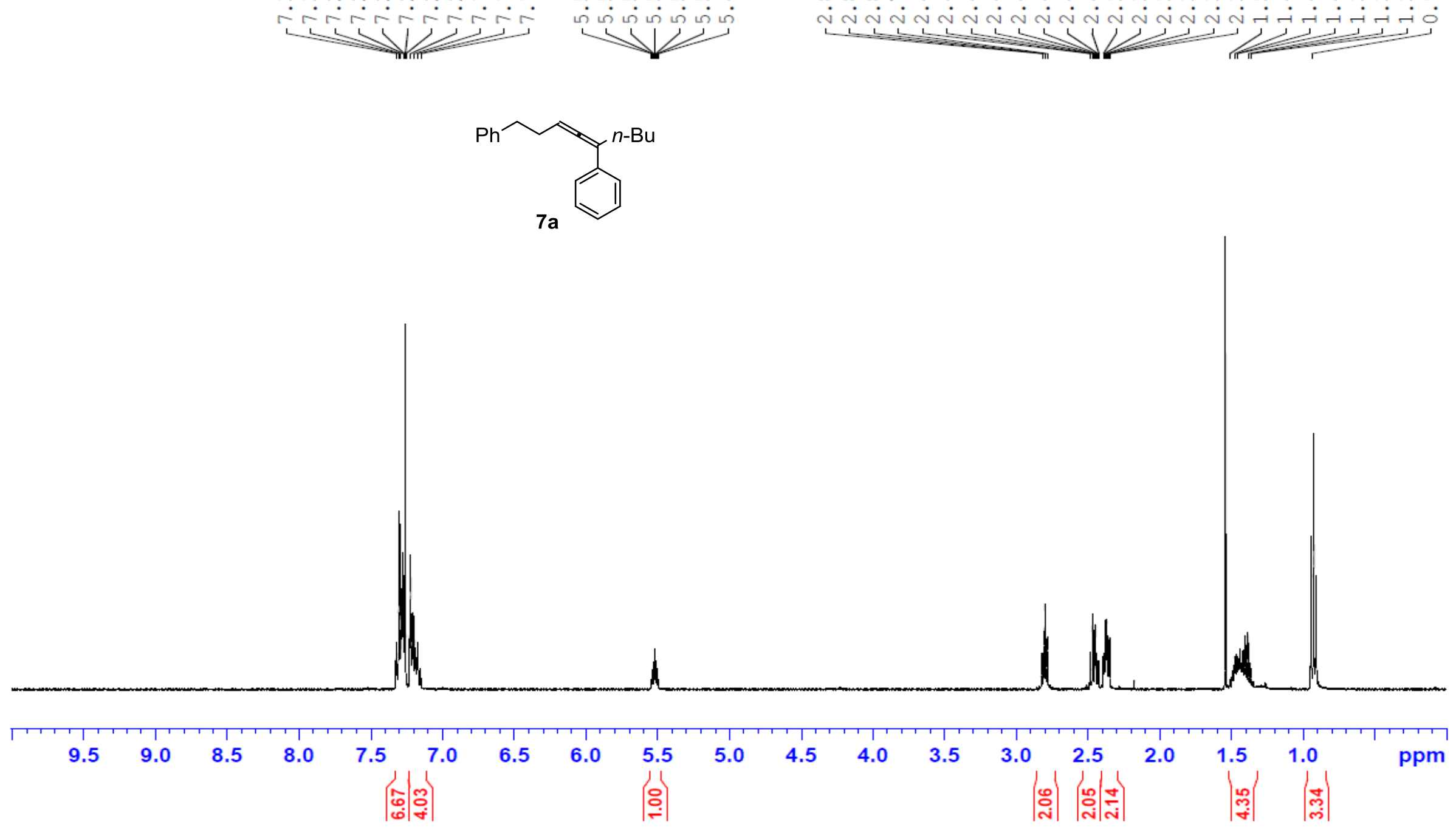

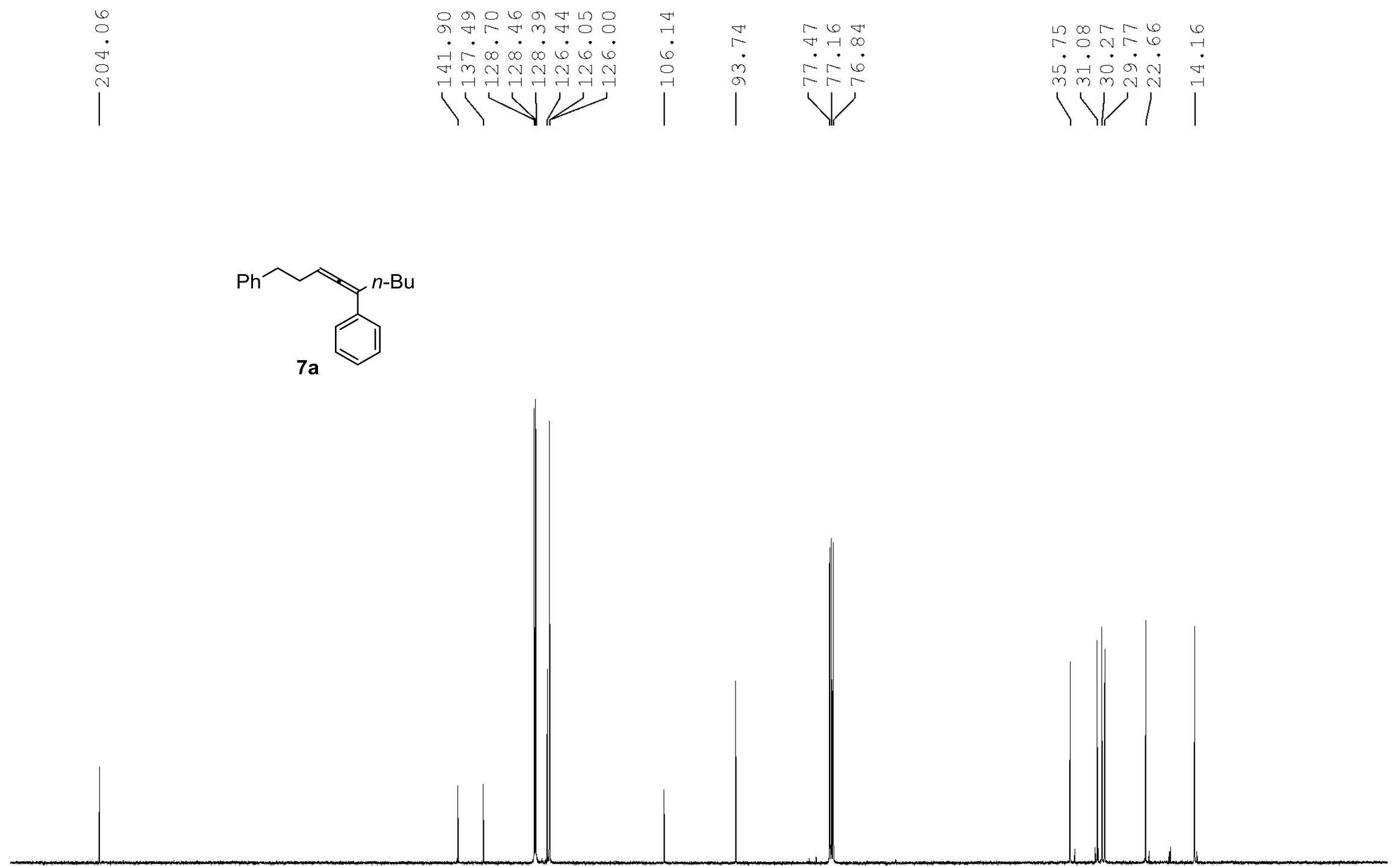

$\begin{array}{lllllllllllllllllllllll}210 & 200 & 190 & 180 & 170 & 160 & 150 & 140 & 130 & 120 & 110 & 100 & 90 & 80 & 70 & 60 & 50 & 40 & 30 & 20 & 10 & 0 & \text { ppm }\end{array}$ 


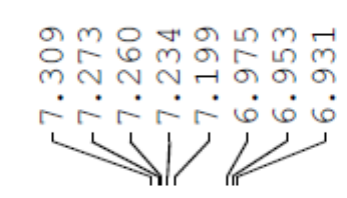

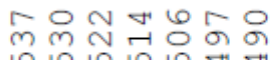

ம்

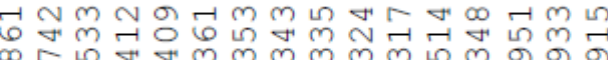
ن

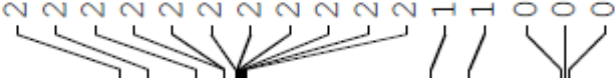
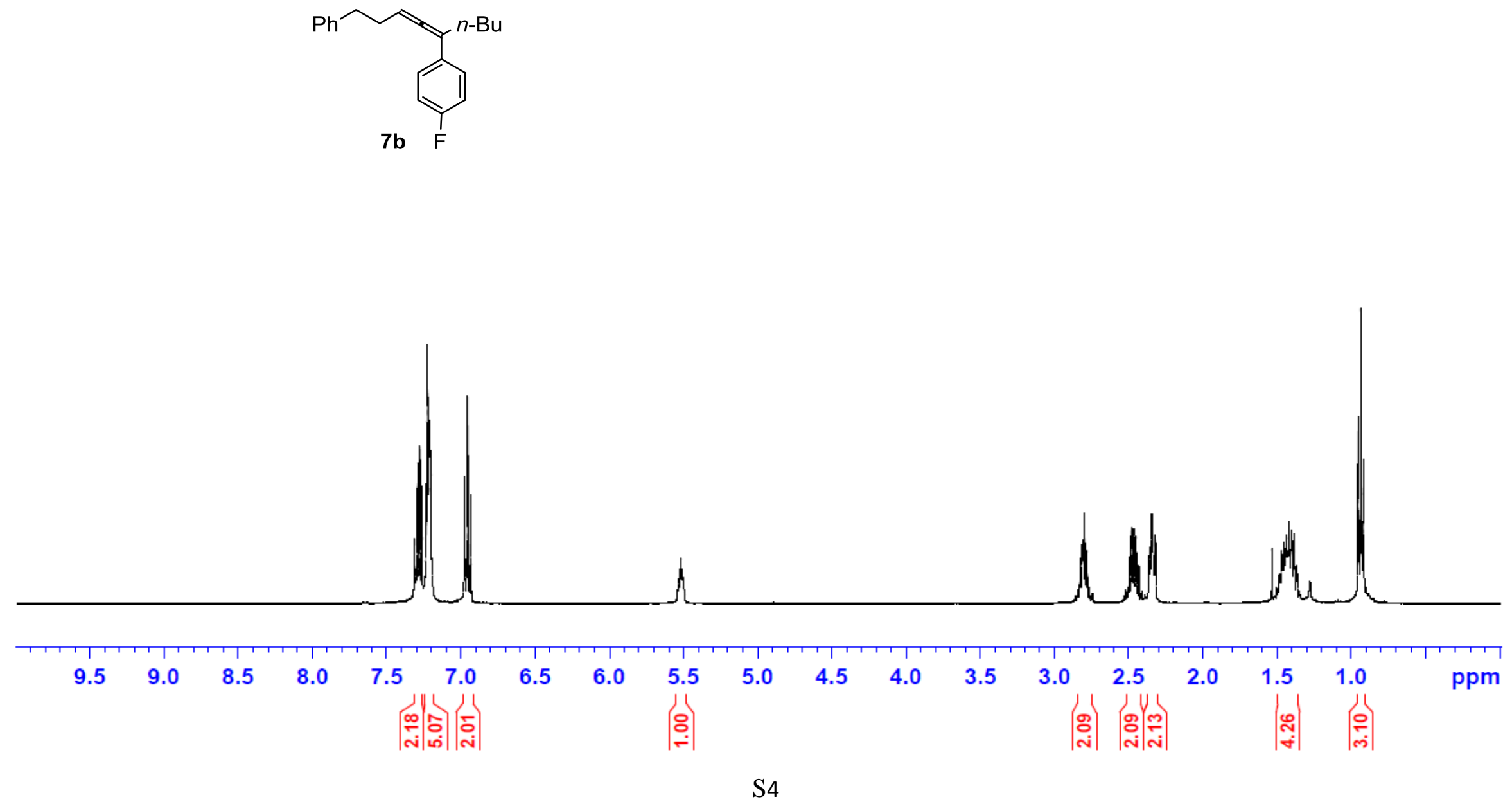

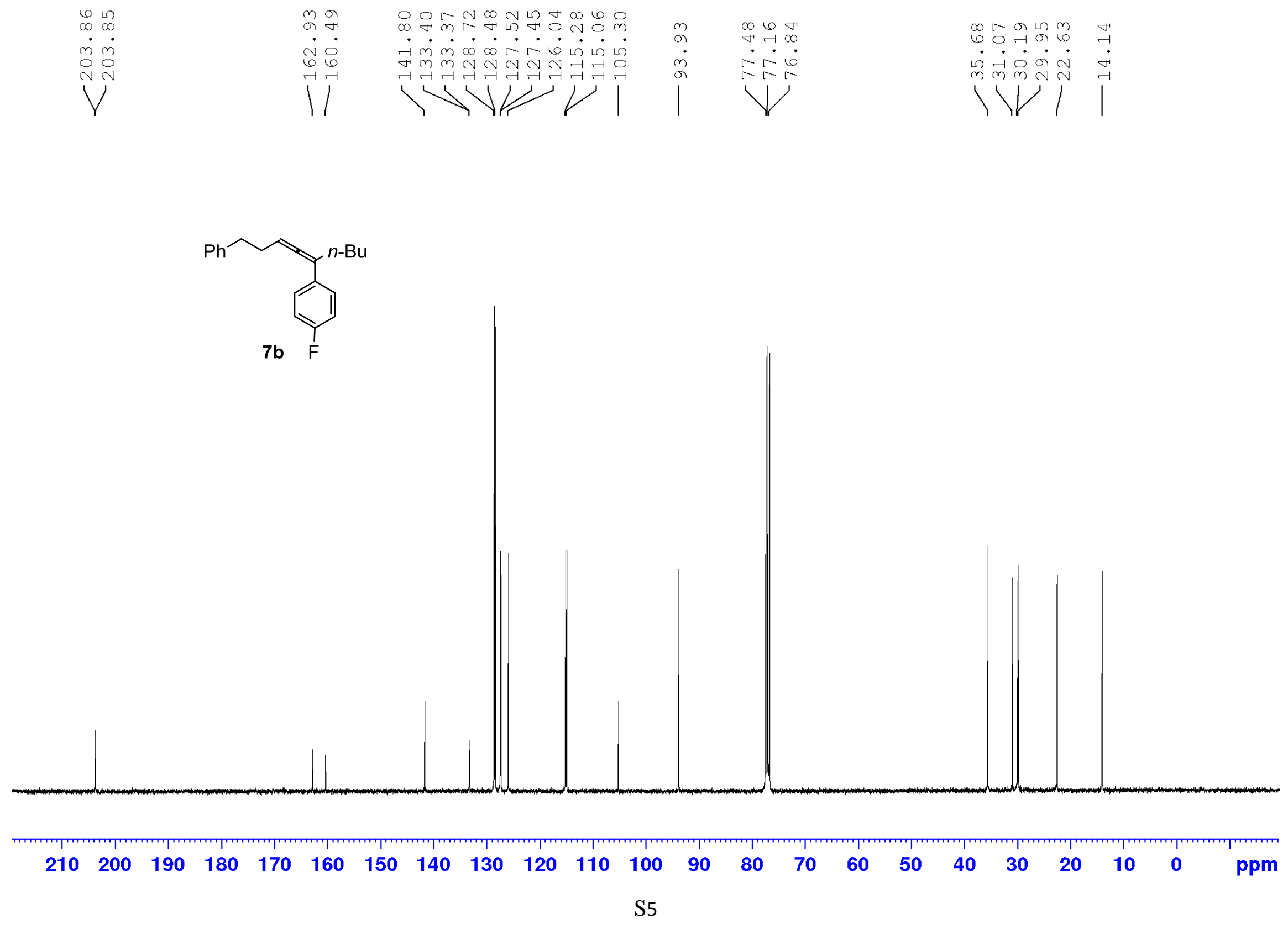


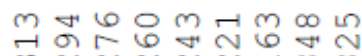

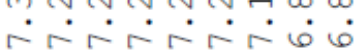

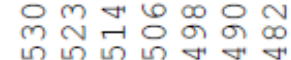

ம்

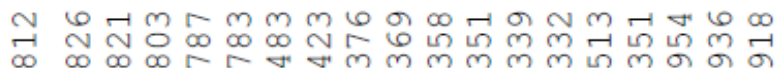

|
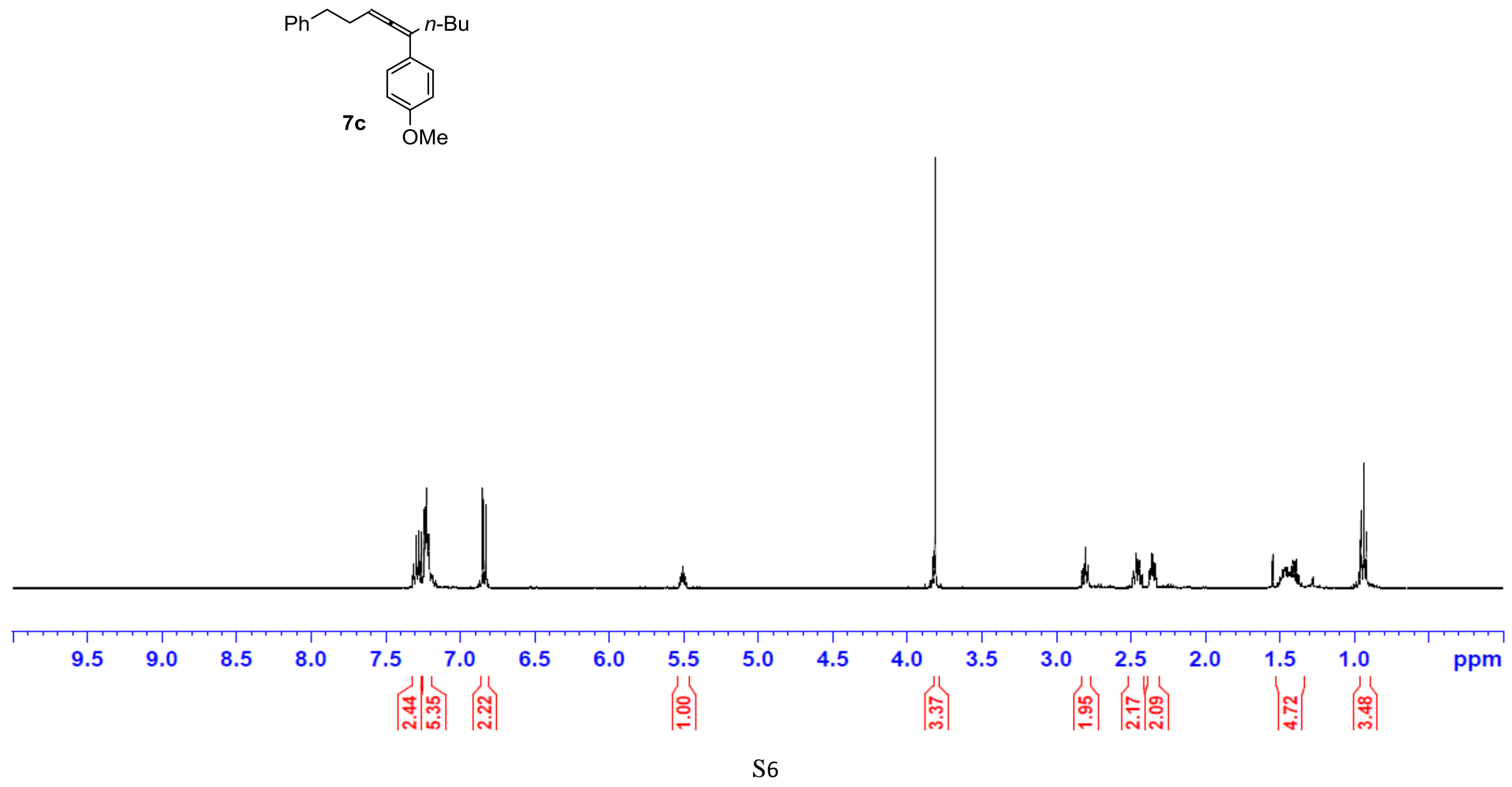


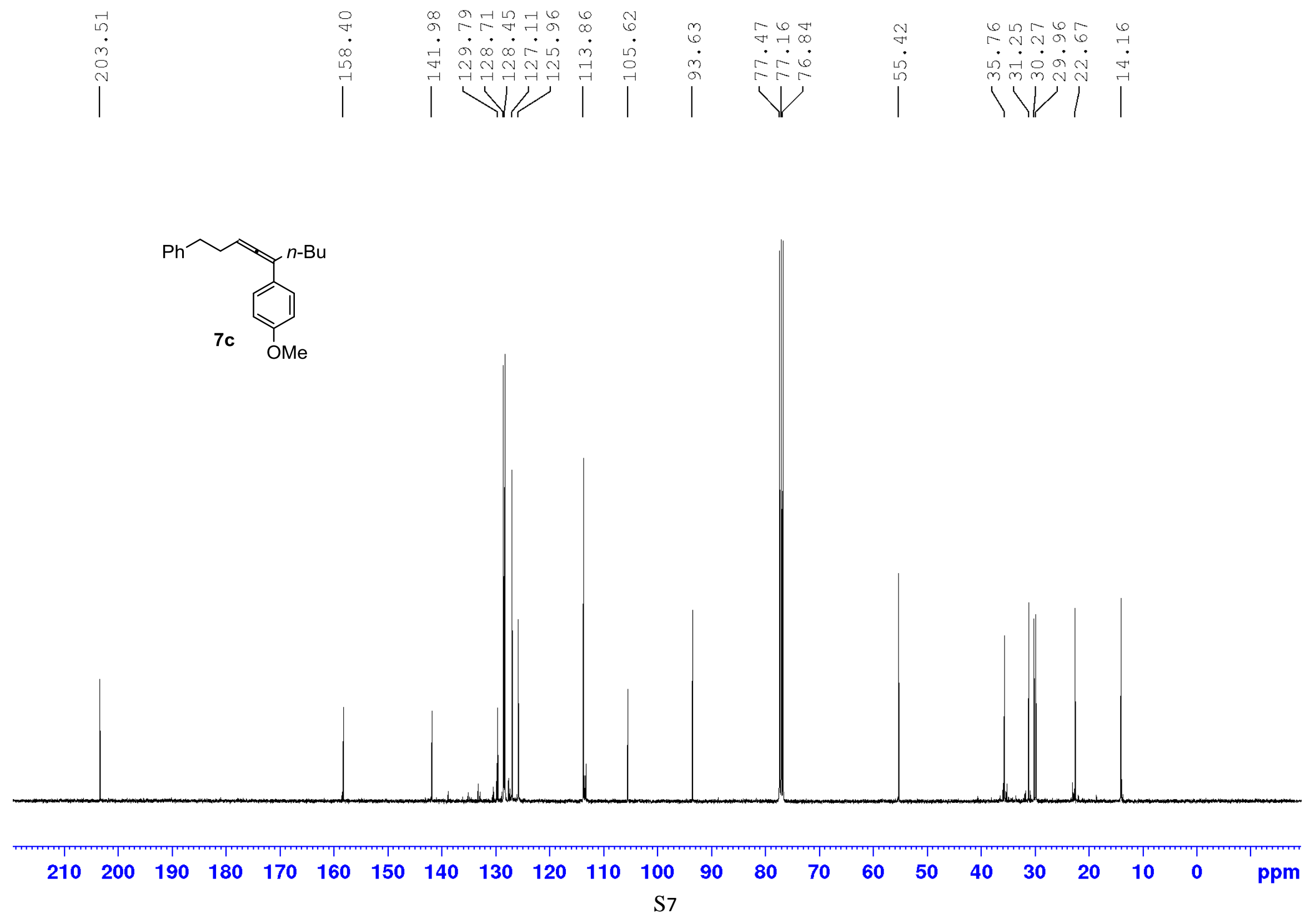




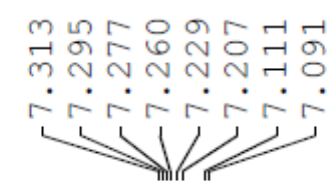

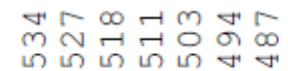

$\dot{0} \dot{0} \dot{0} \dot{0} \cdot$

$\underbrace{n}$

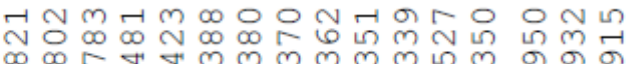

$\underbrace{\dot{N} \sim} \dot{N} \dot{N} \dot{N} \dot{N} \vec{i} \dot{0}$
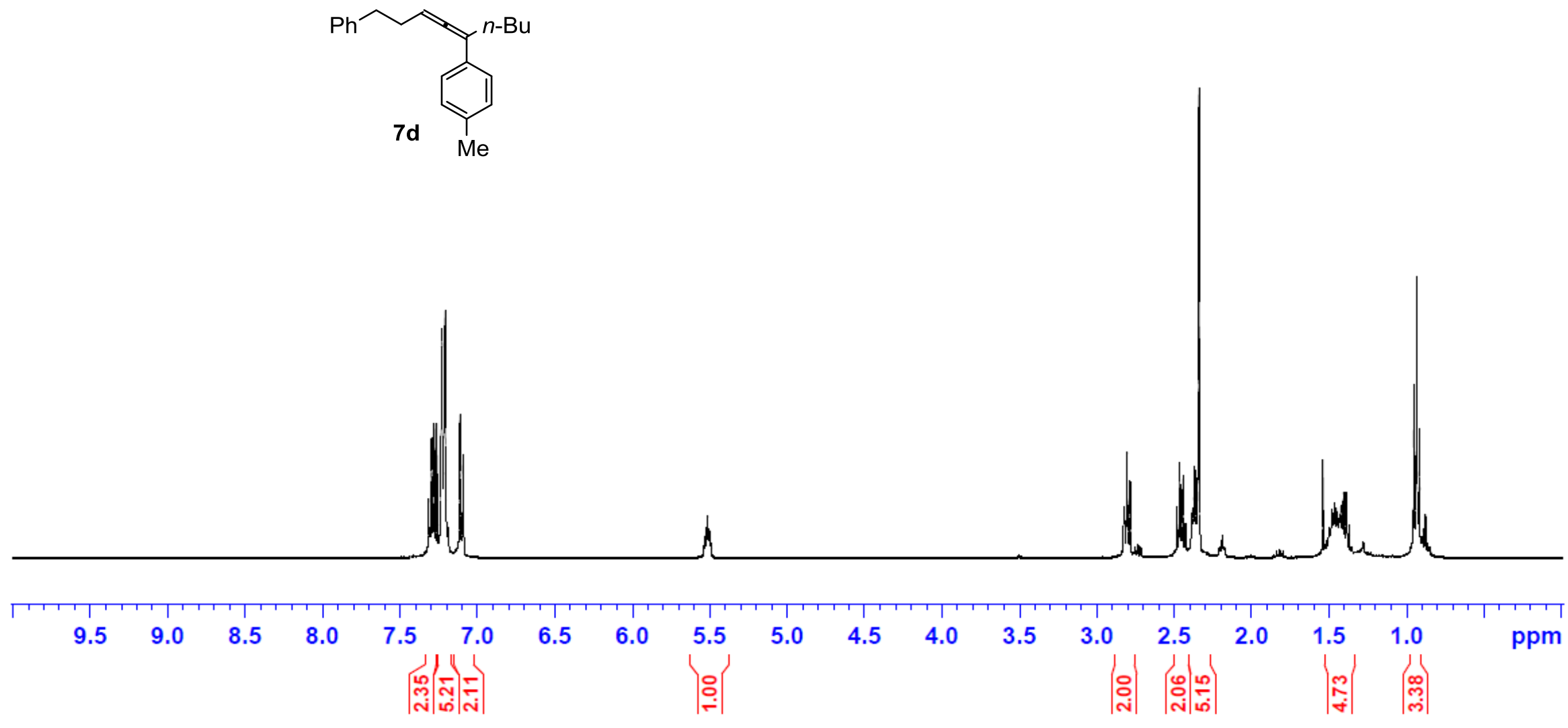


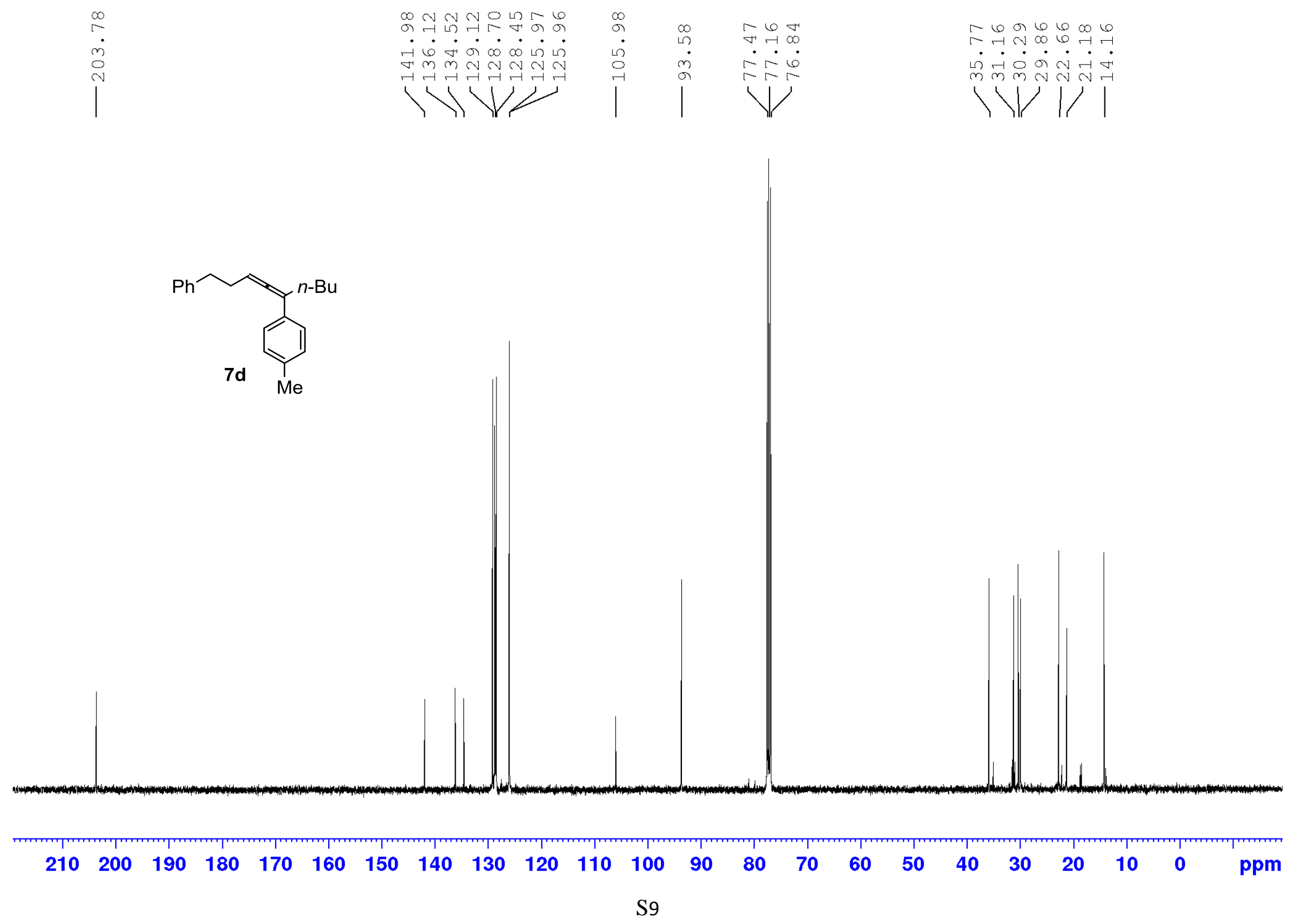



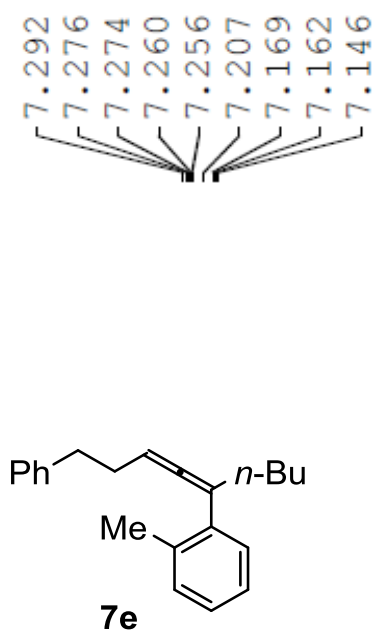

$7 e$

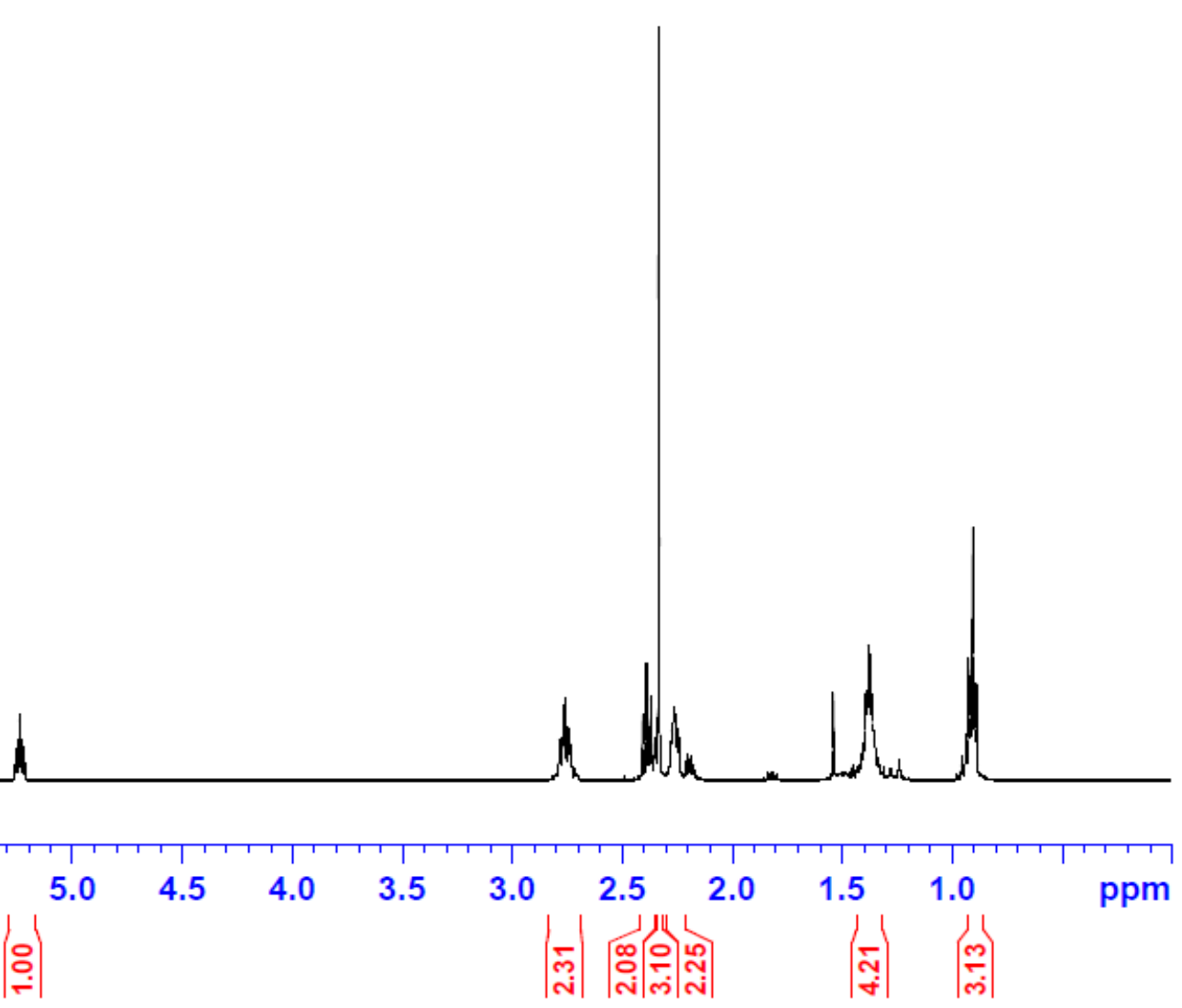



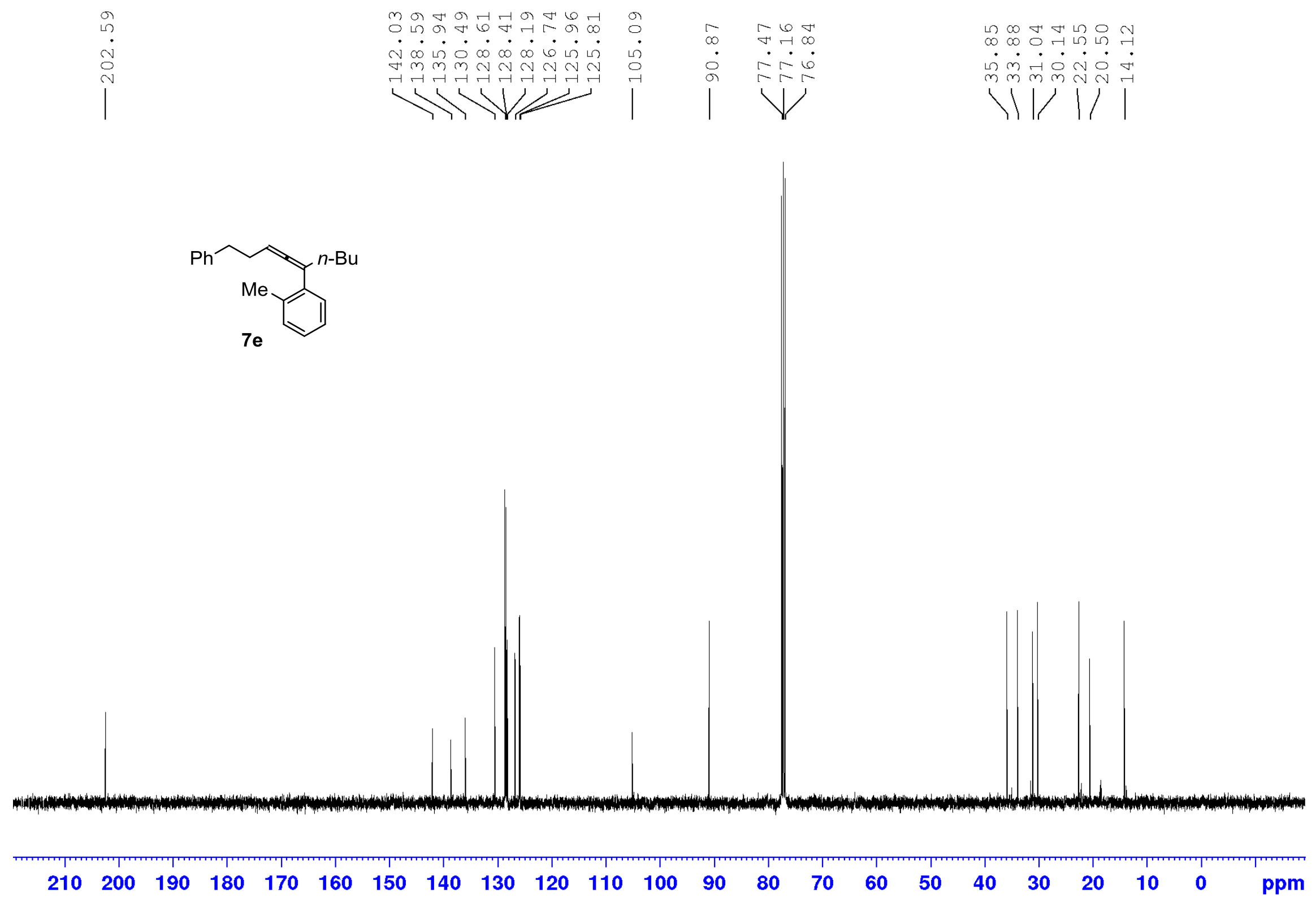


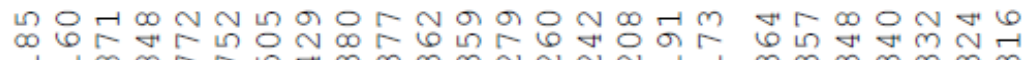

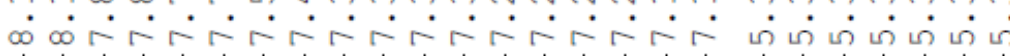

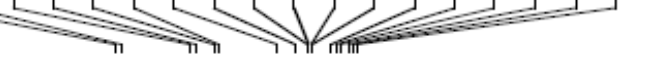

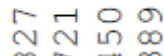
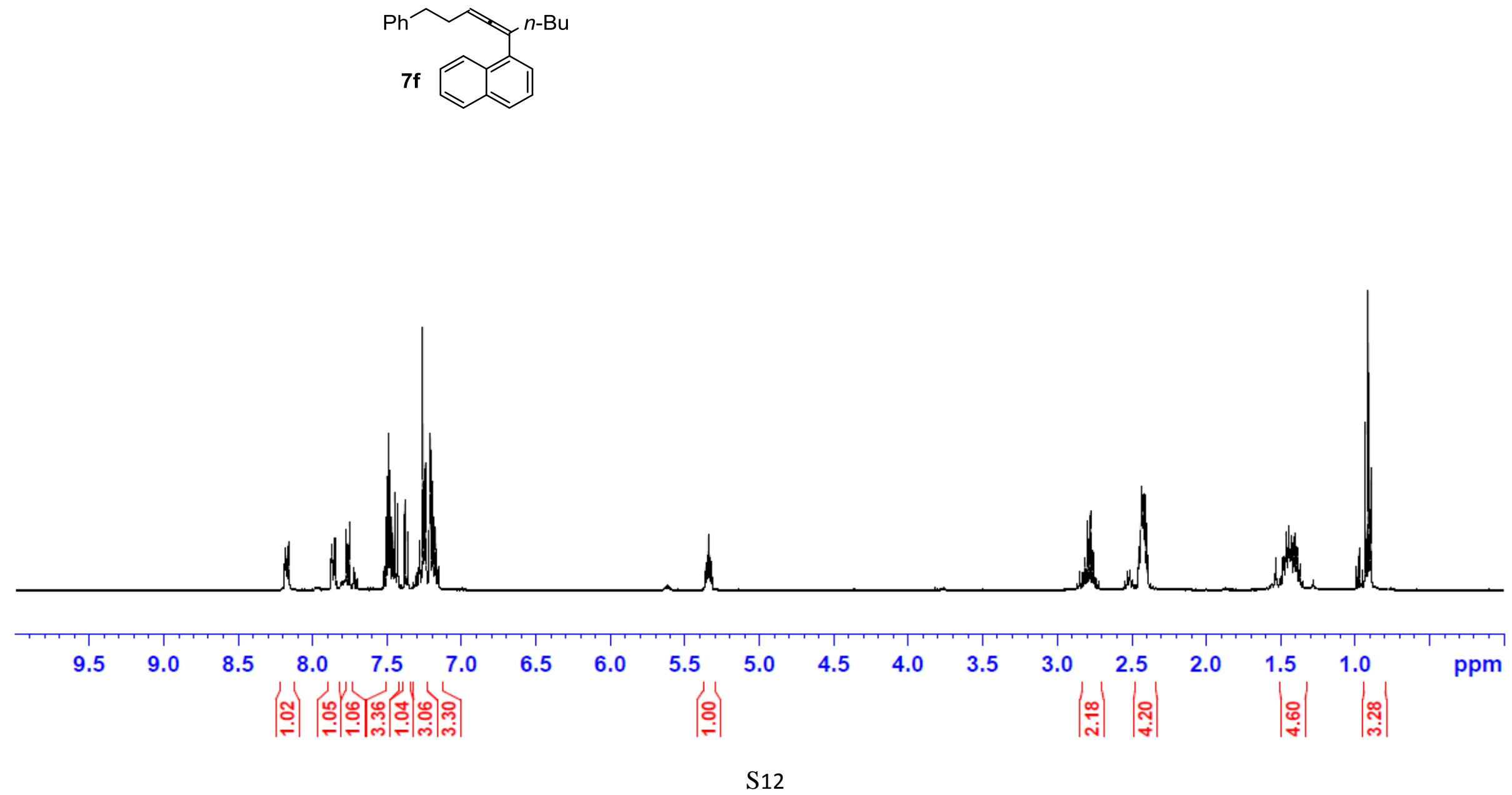

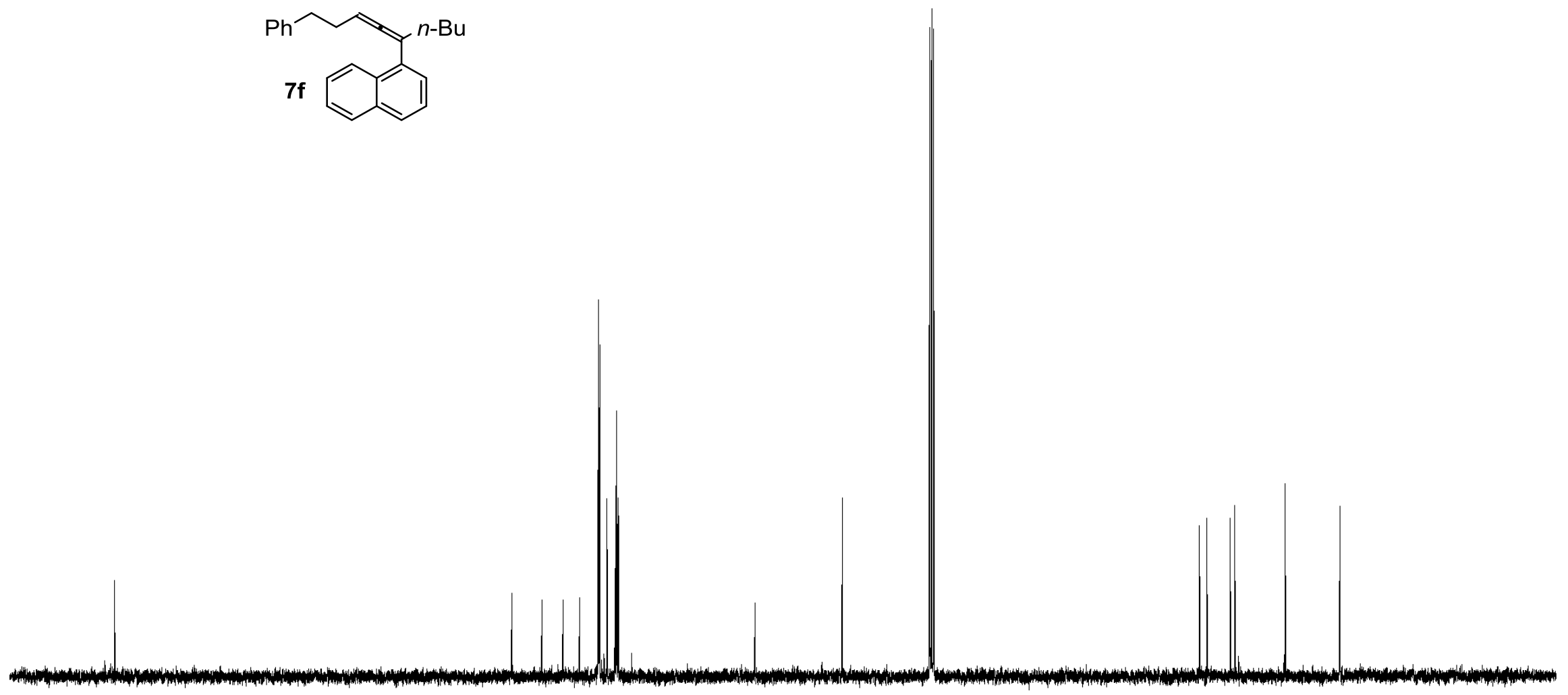


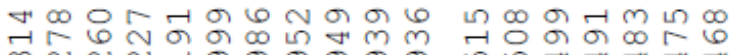

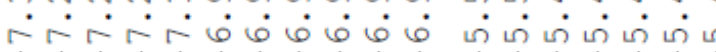

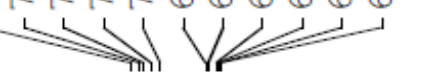

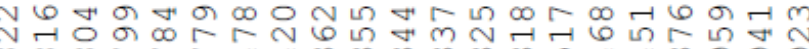

$\dot{N} \dot{\sim} \dot{N} \dot{N} \dot{N} \dot{N} \dot{N} \dot{N} \dot{\sim}-\dot{j} \dot{0} \dot{0}$

13
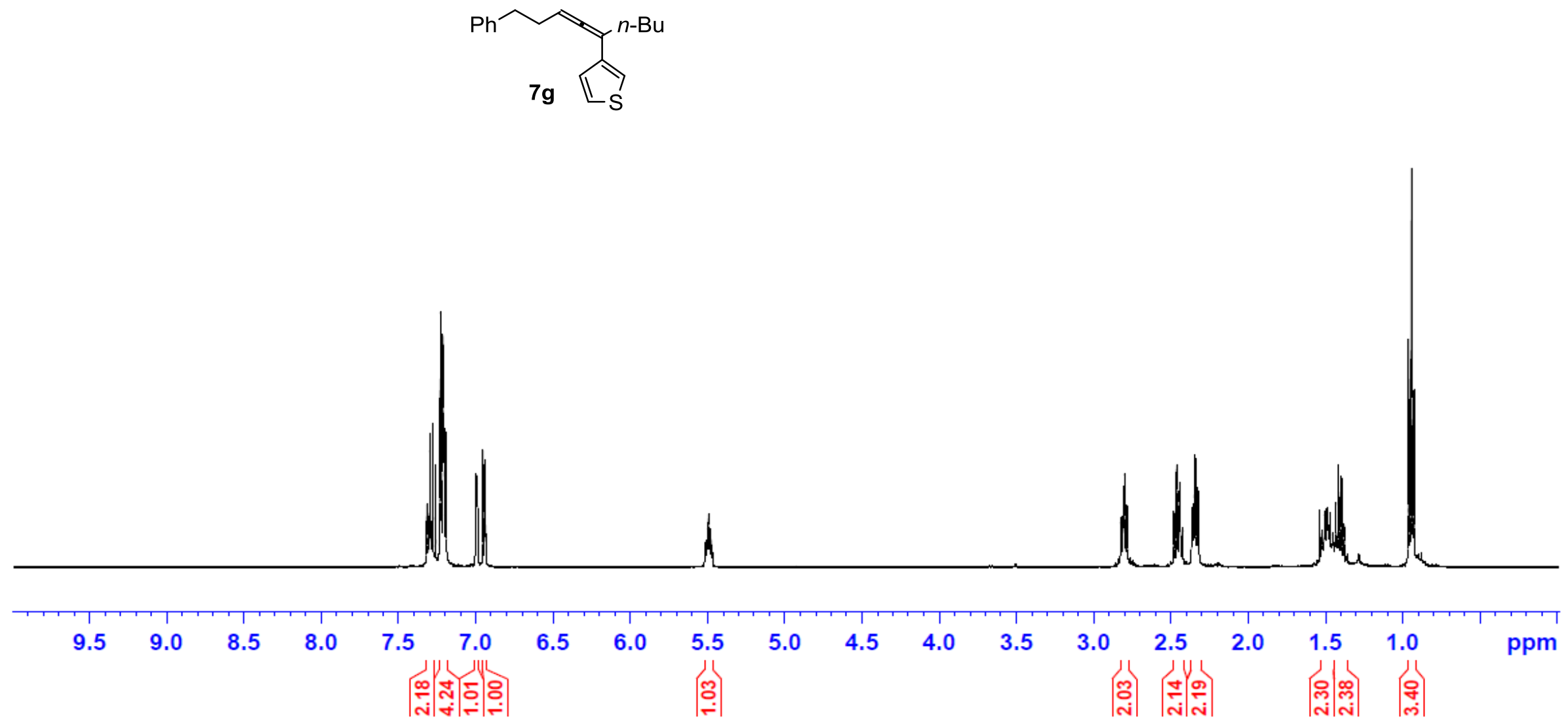

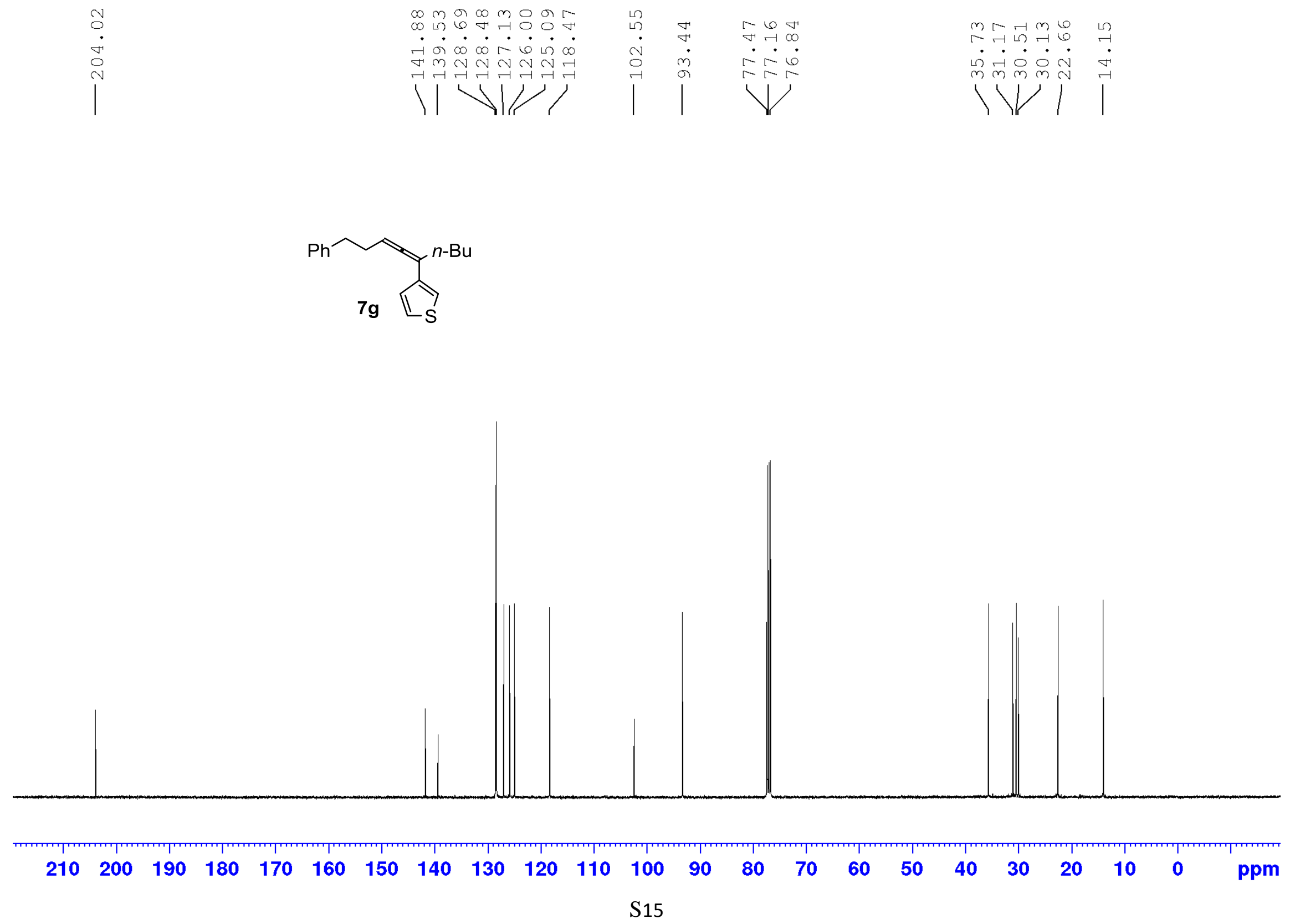

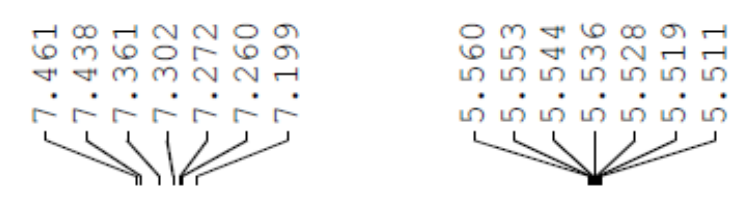

అம ๑ Ni)
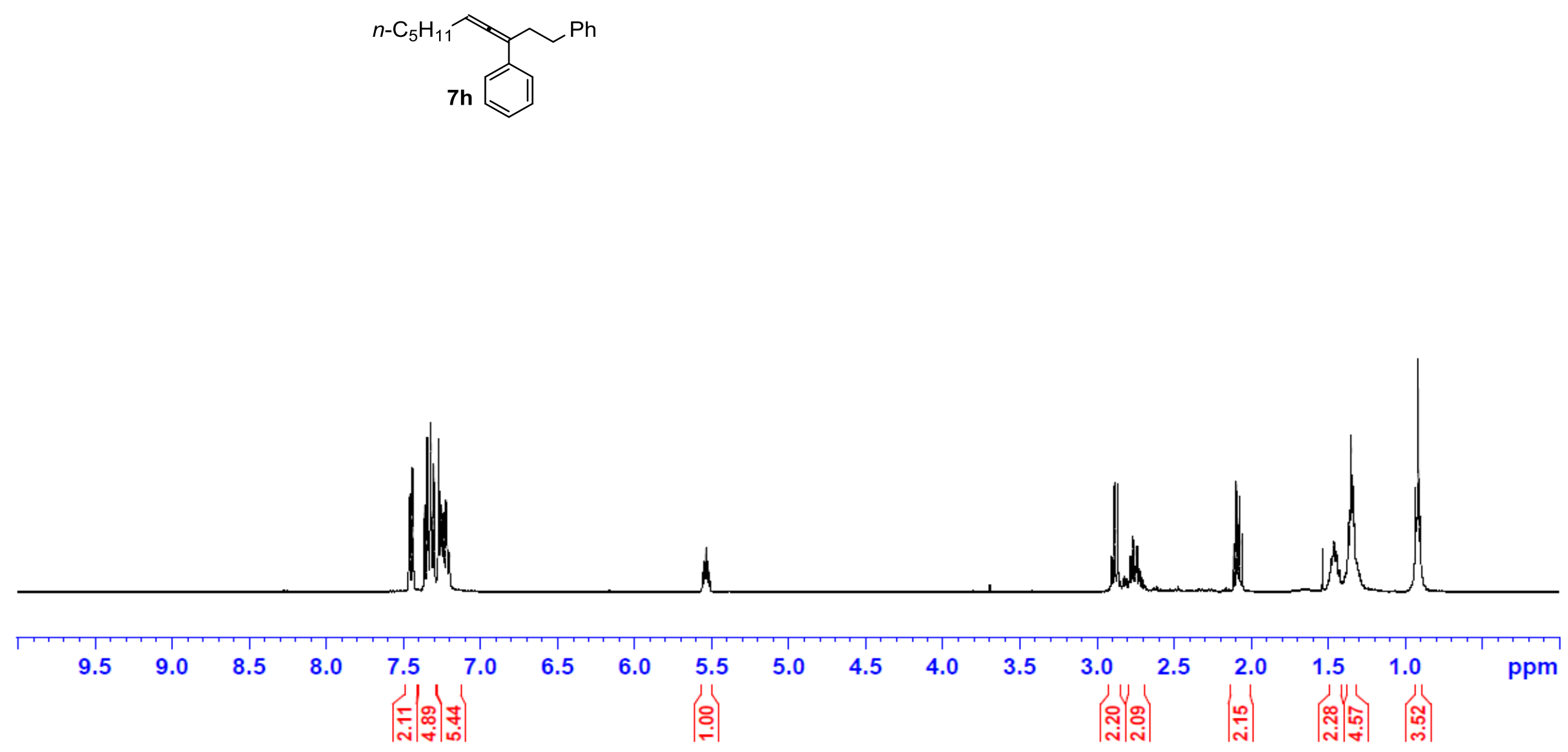


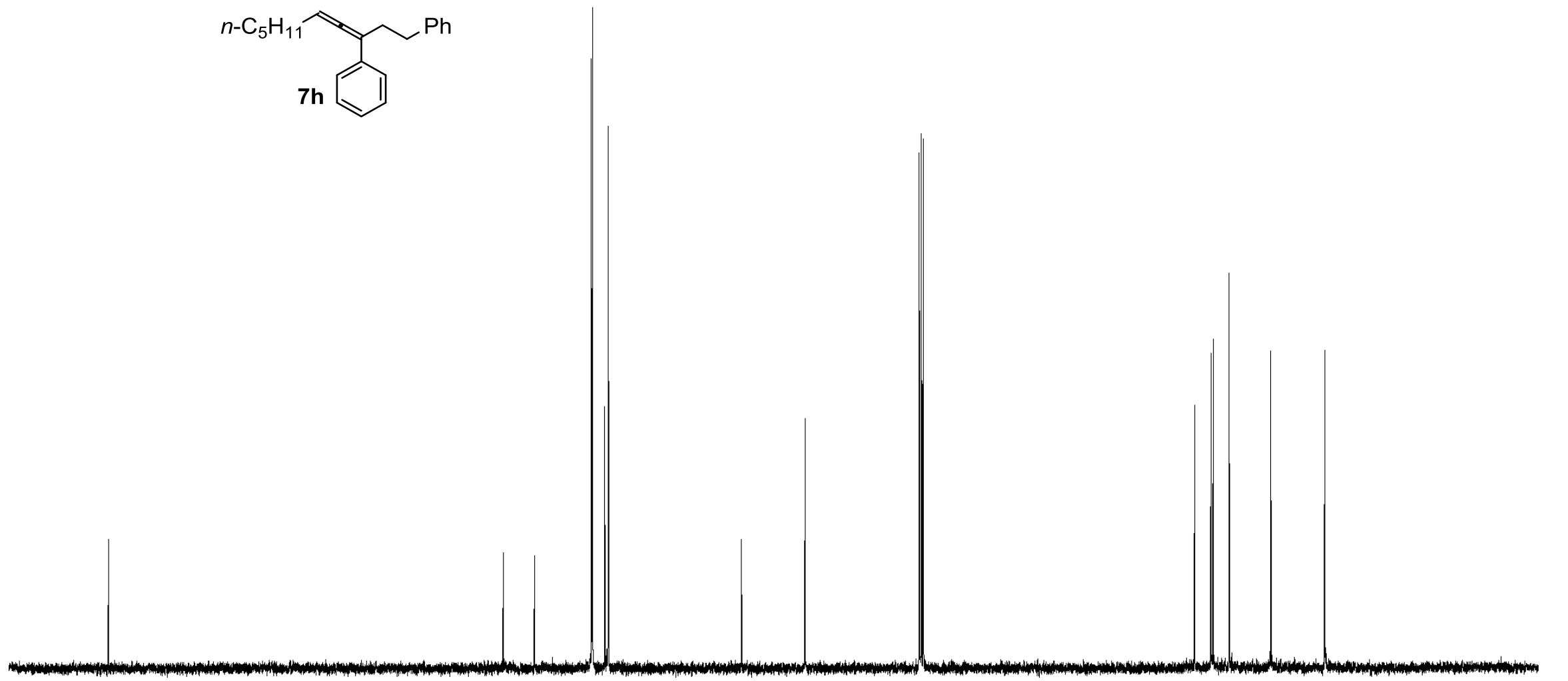




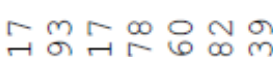

$\forall m m N \rightarrow-$

$\operatorname{crs} 25$

S1)

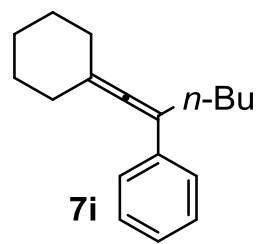

Uht

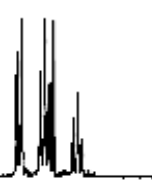

the ine

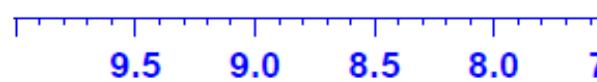

$7.5 \quad 7.0$

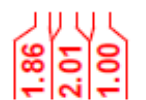

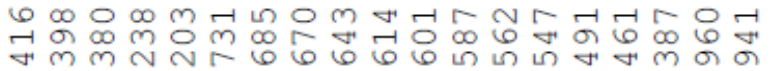

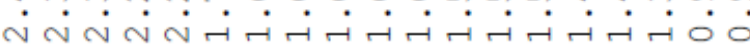
की

$\begin{array}{lll}9.5 & 9.0-8.5 & 8.0\end{array}$ 


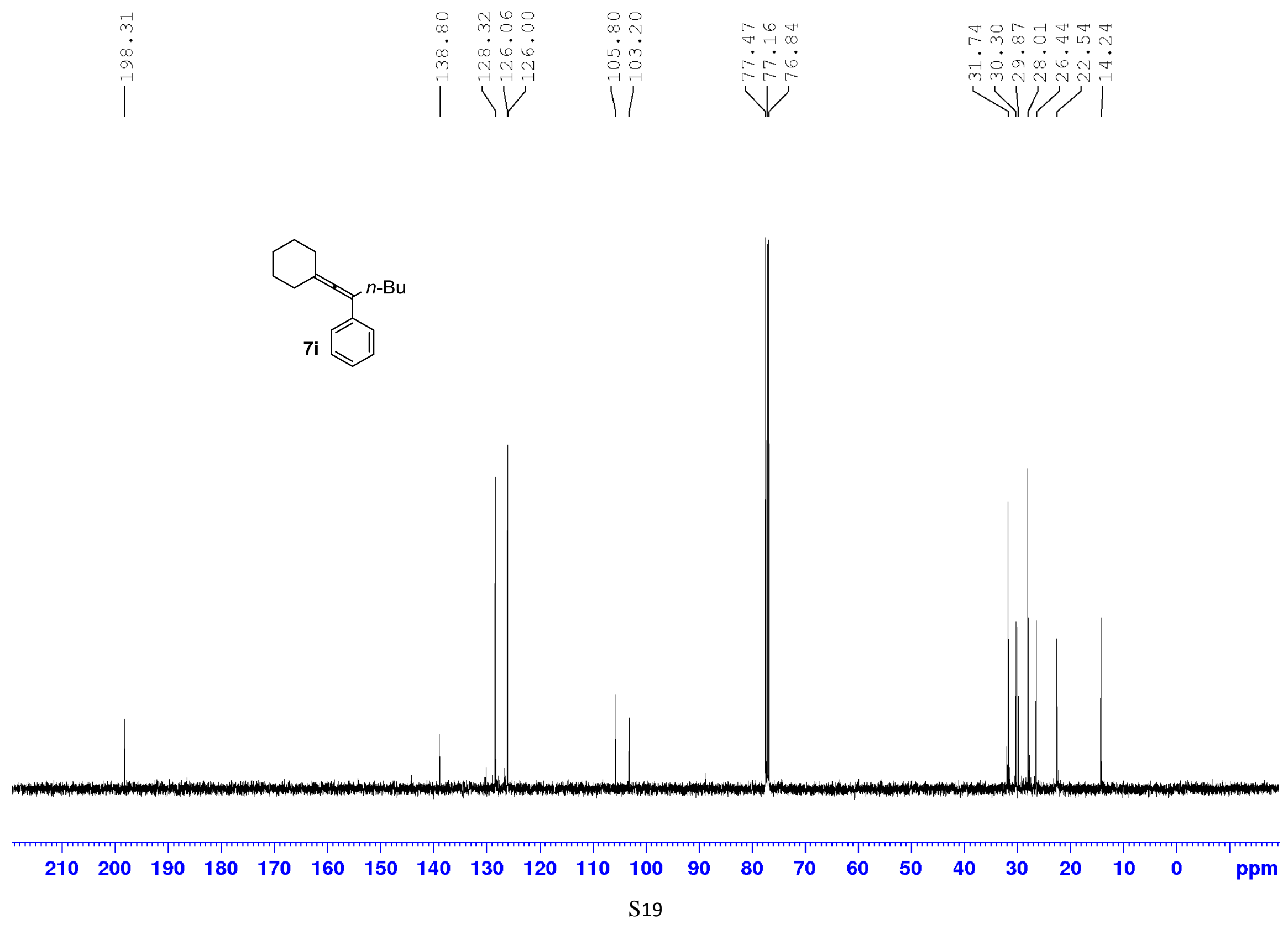




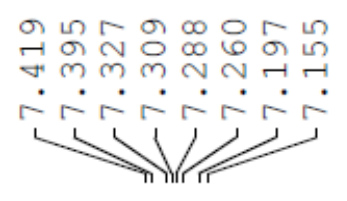

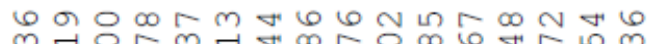
4.

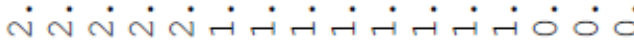
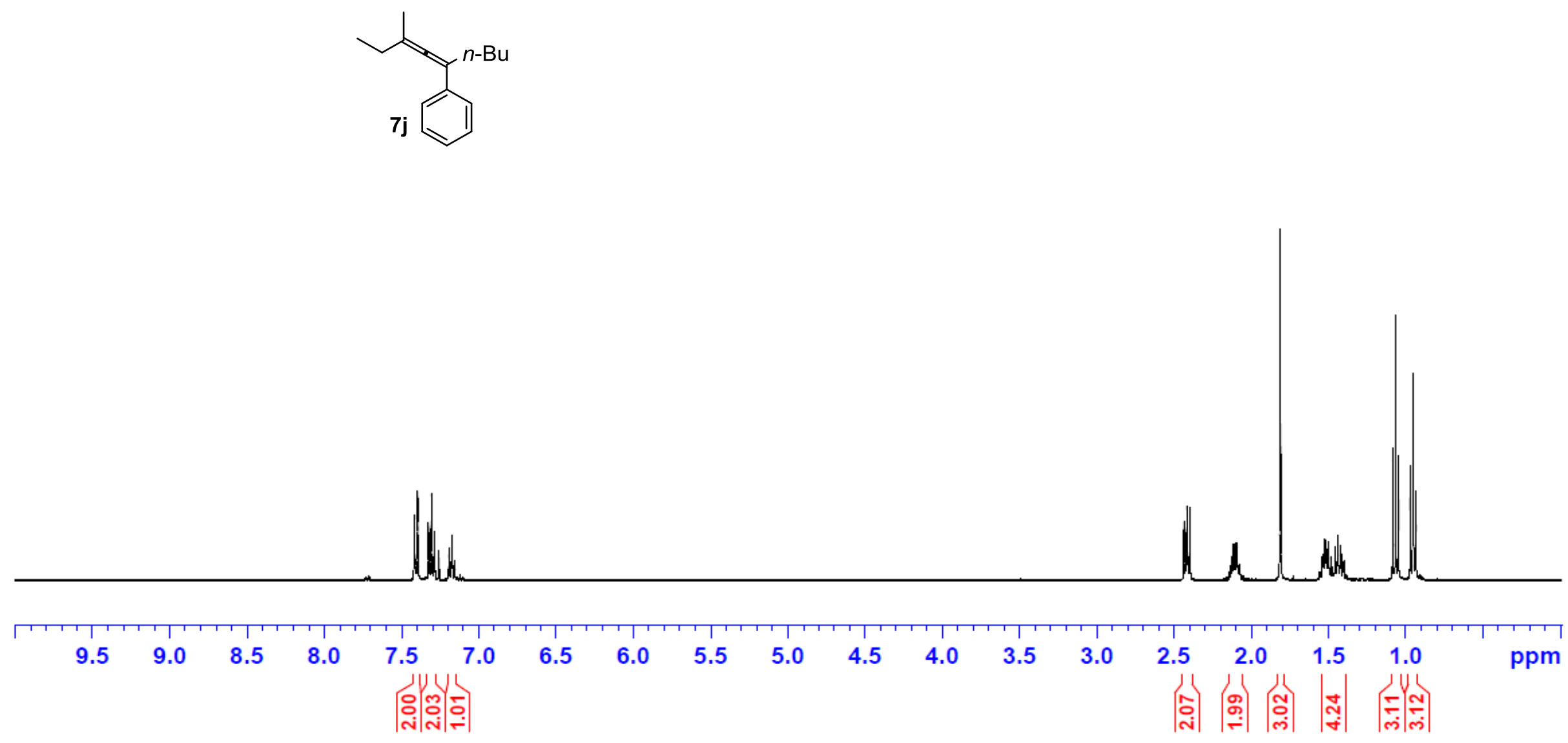


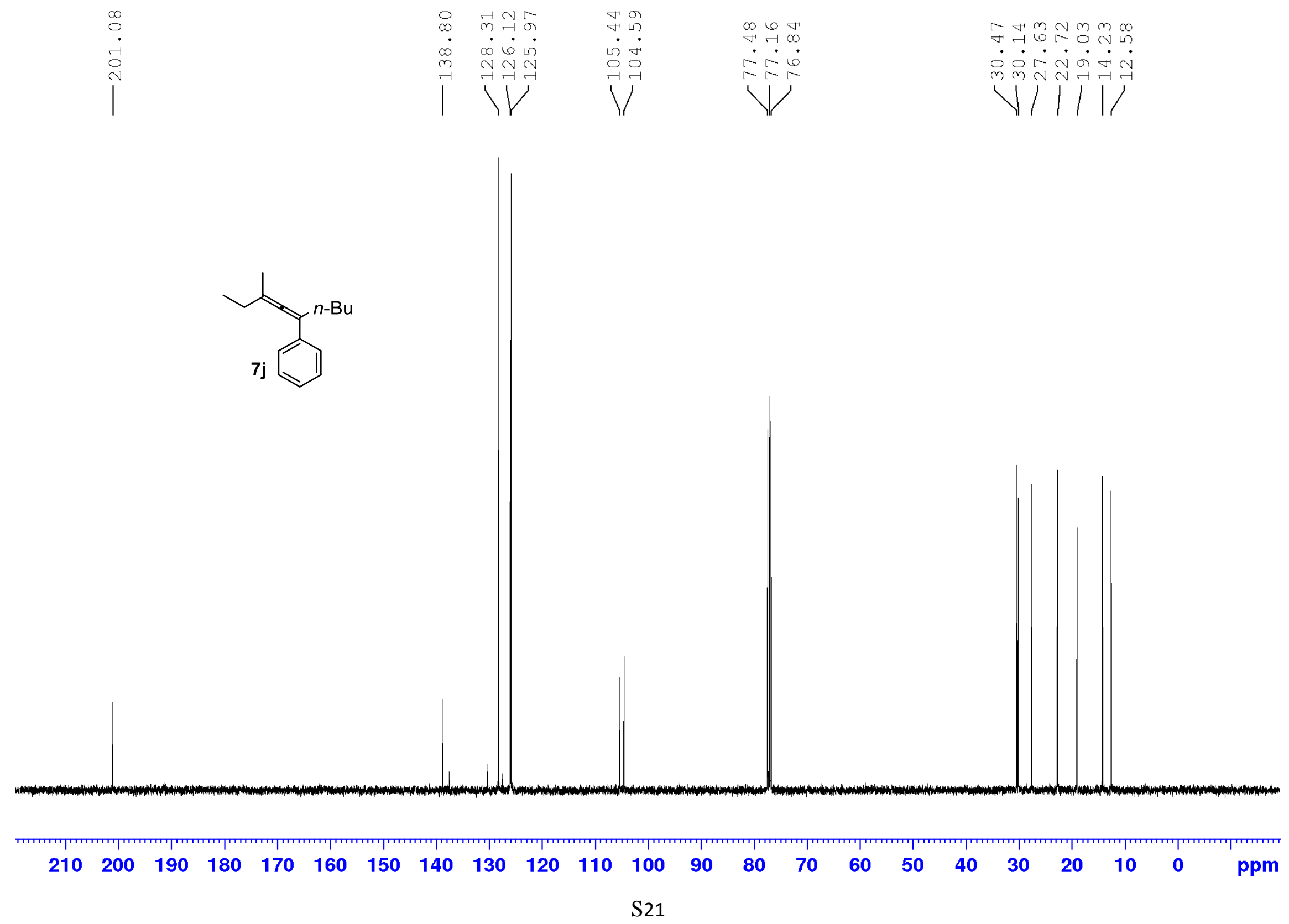



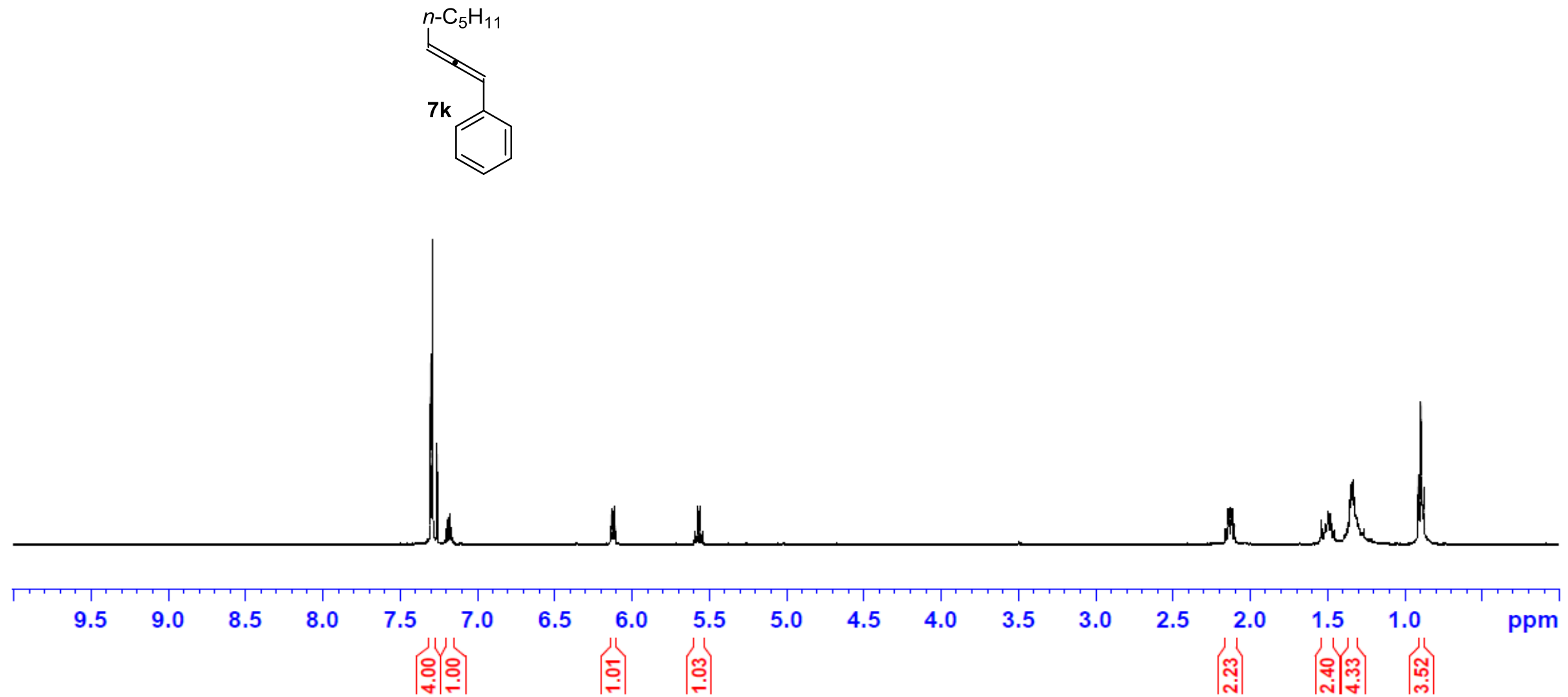


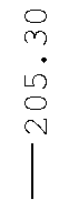

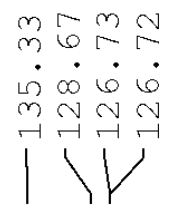

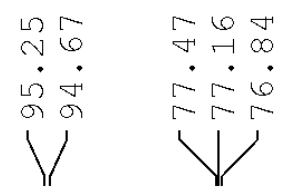

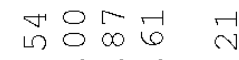
$\dot{m} \dot{\sim} \dot{\infty} \stackrel{\sim}{N}$
$|V|$
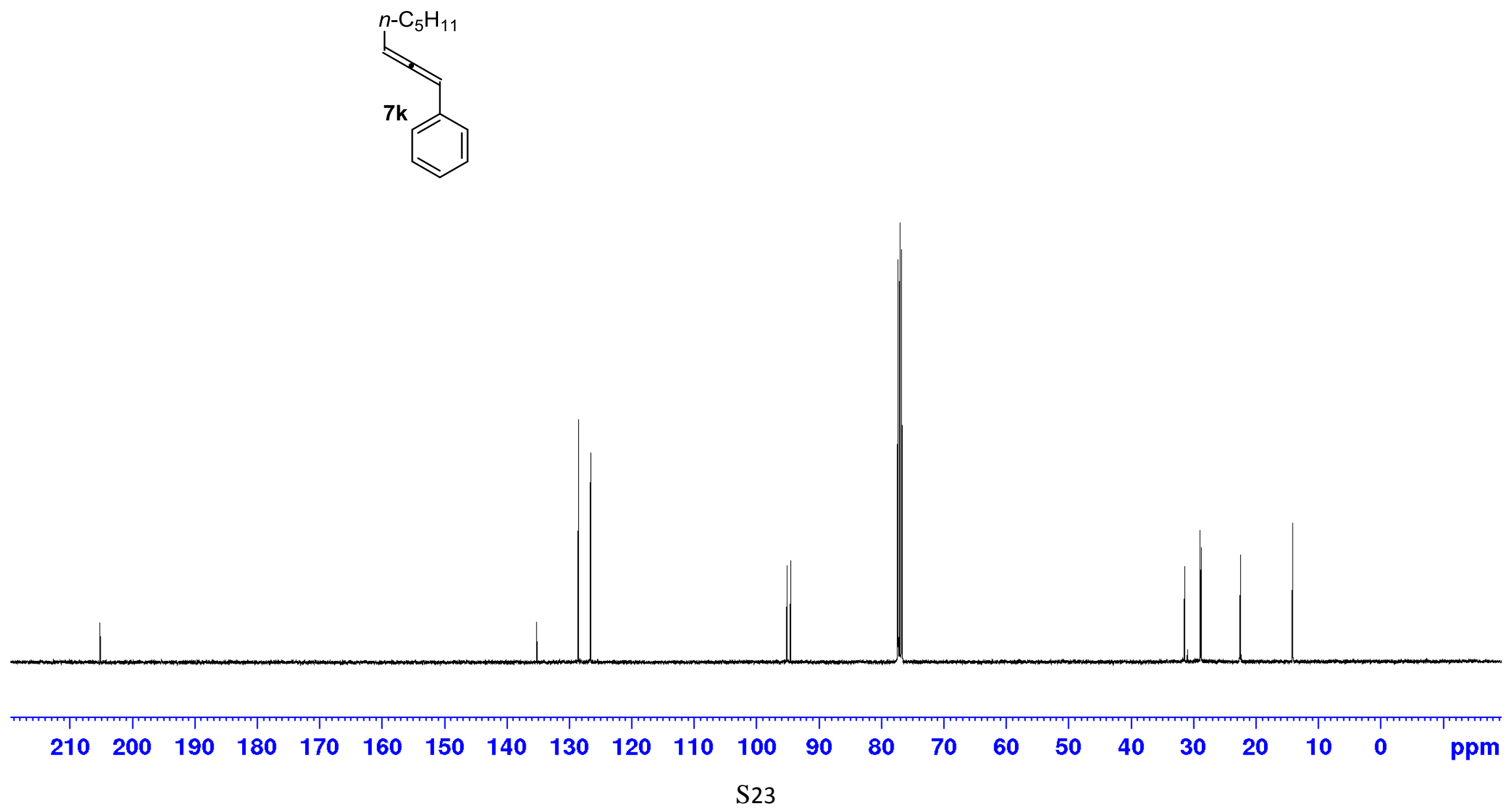

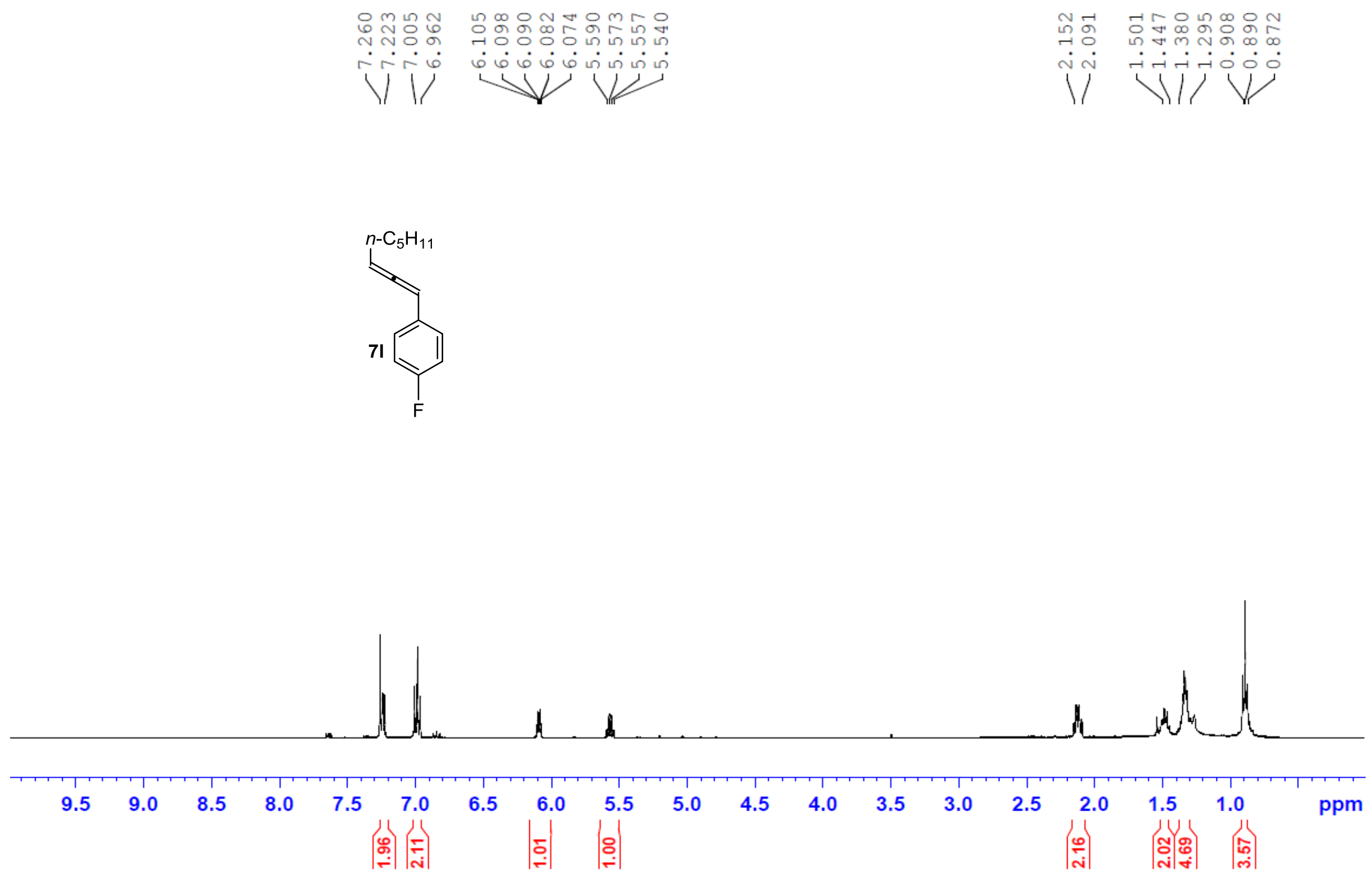


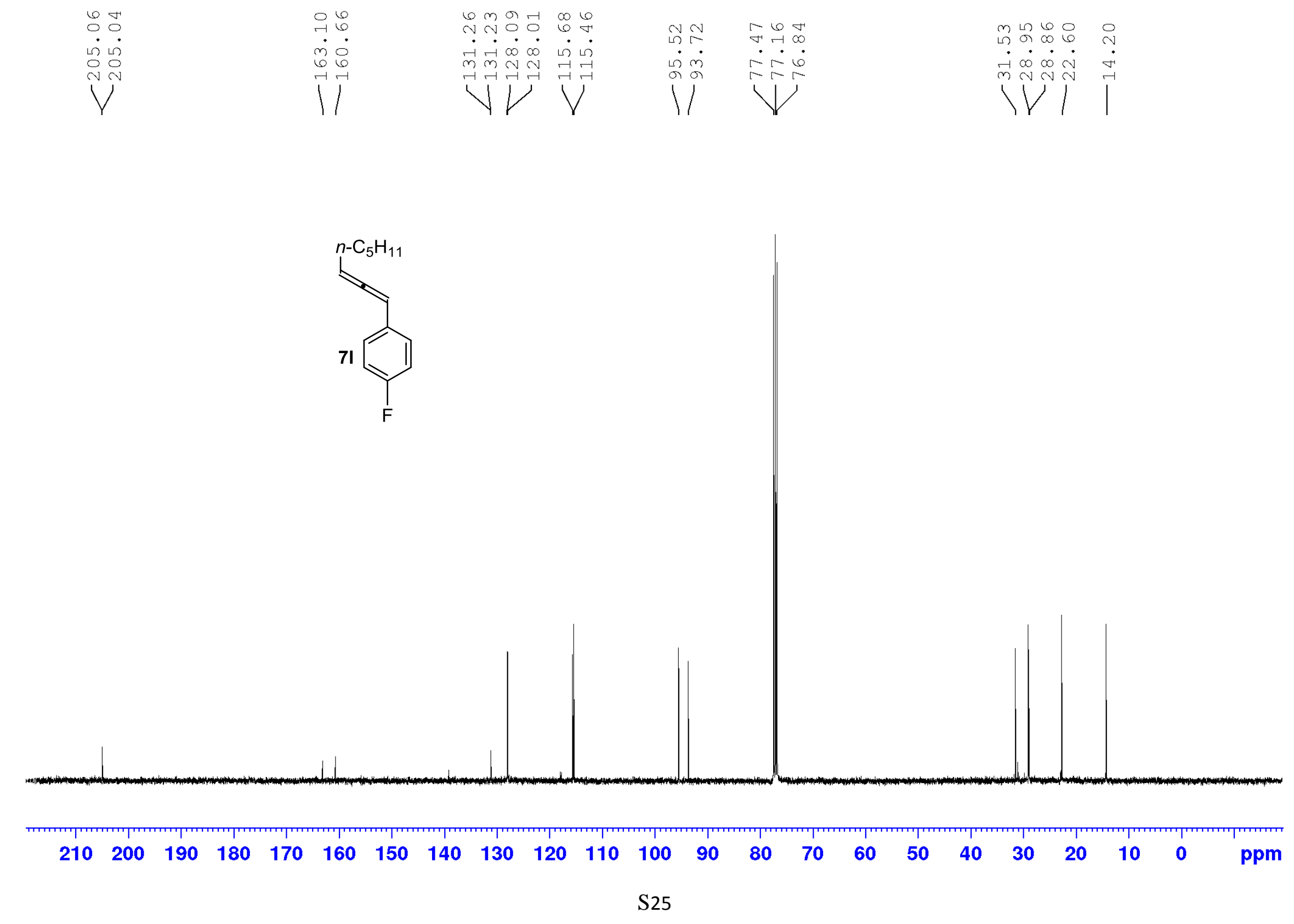


ஊ

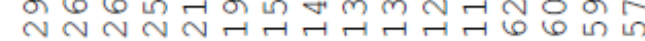

rrrrrí

$\$ N$

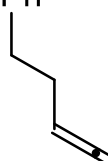

$7 \mathrm{~m}$

$7 \mathrm{~m}$

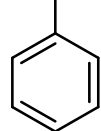

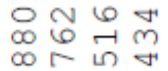

$\dot{i} \dot{i} \dot{i} \dot{r}$

111
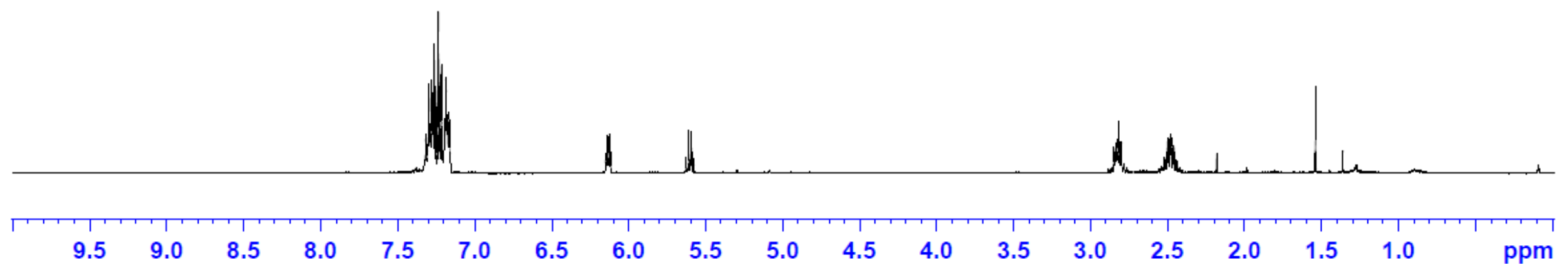

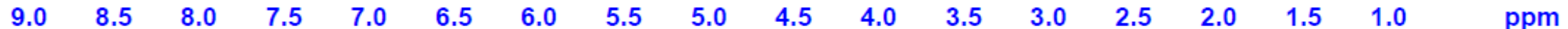

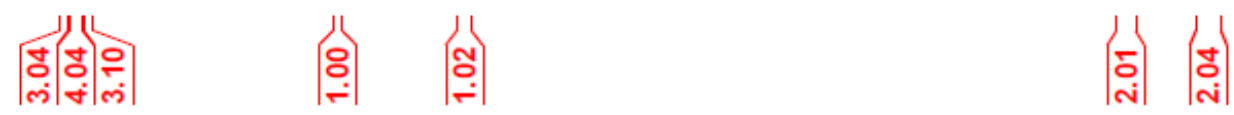



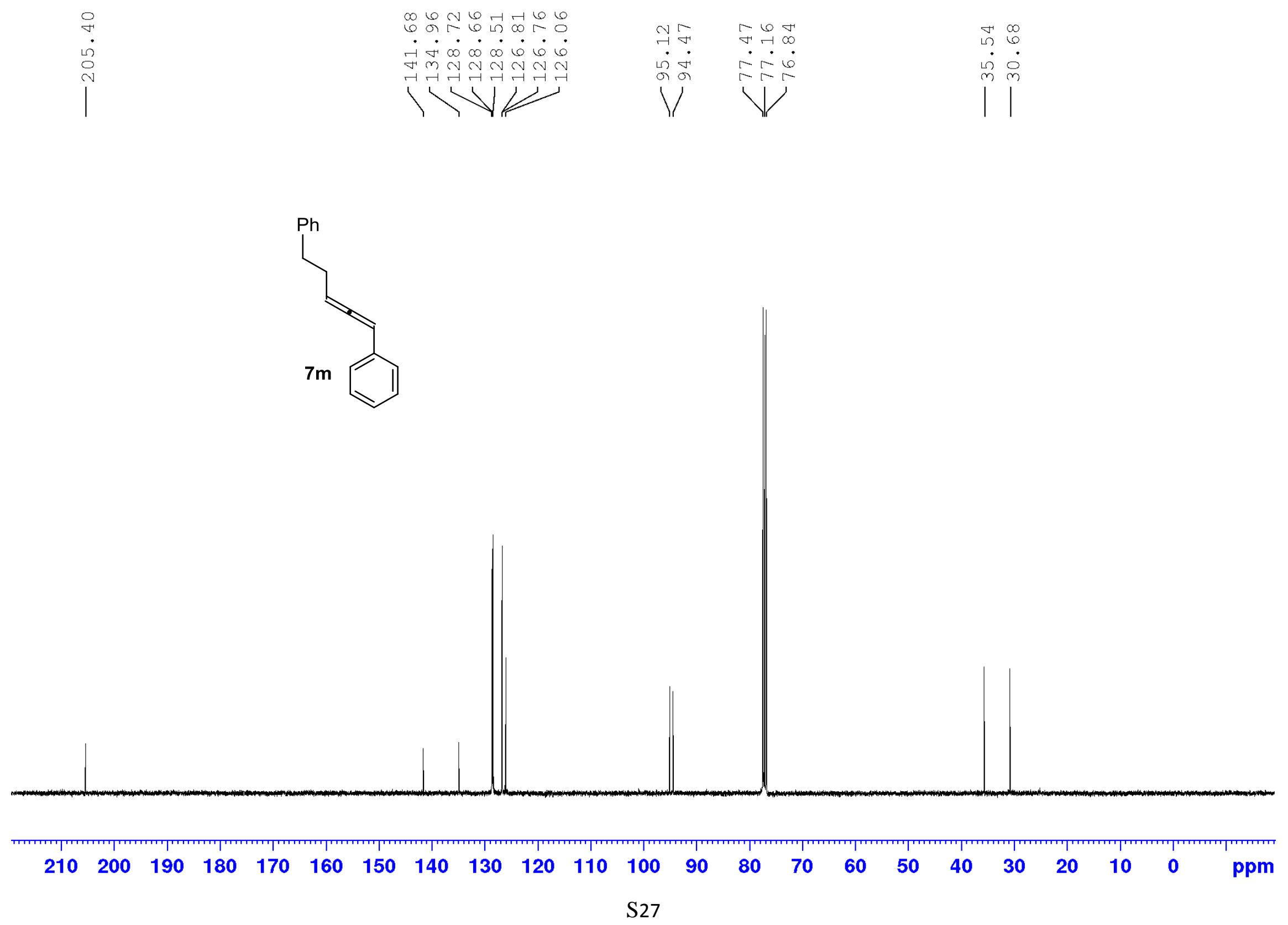


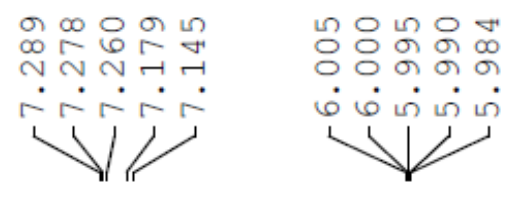

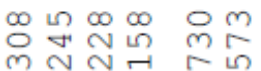

रूंख̃ |ं।
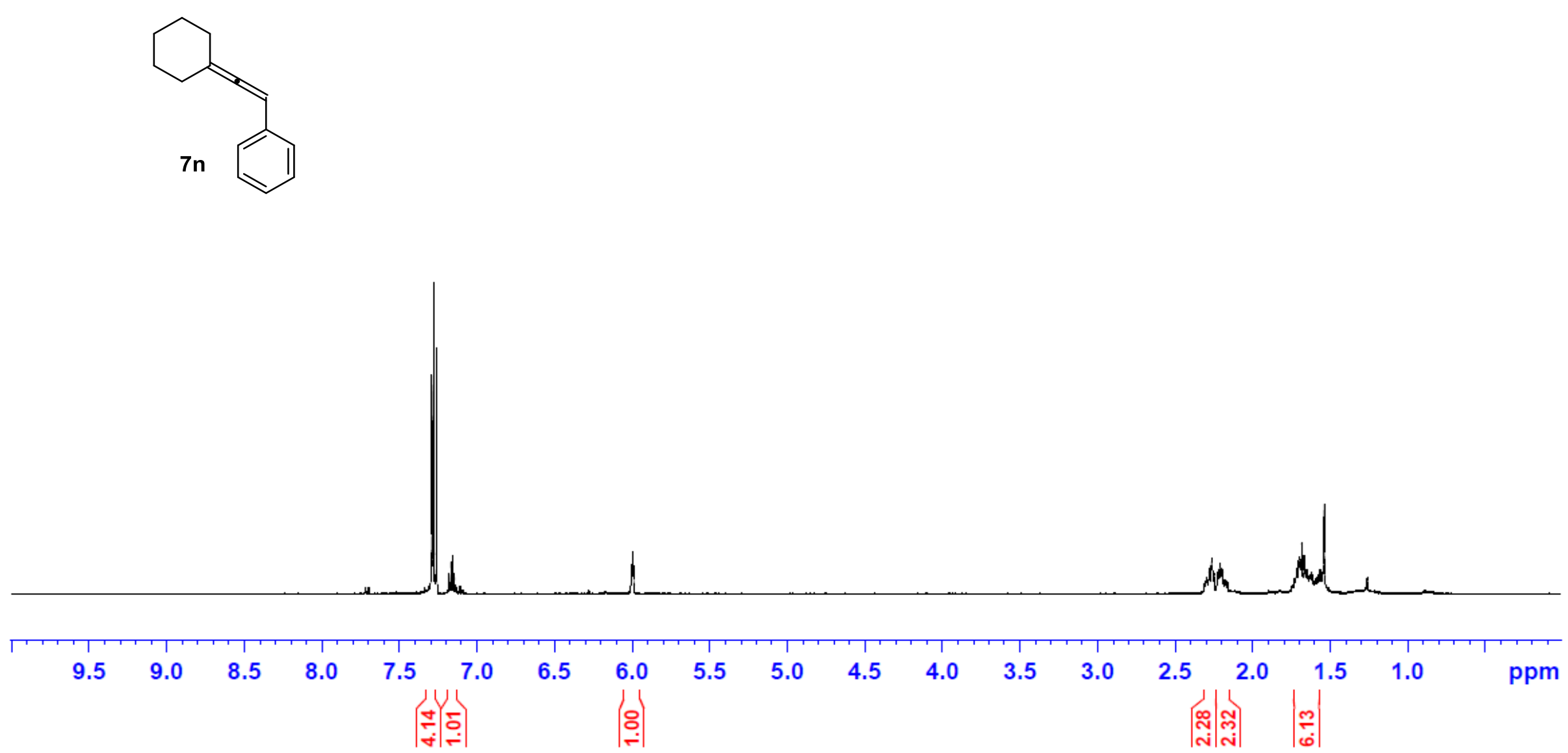


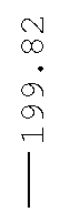
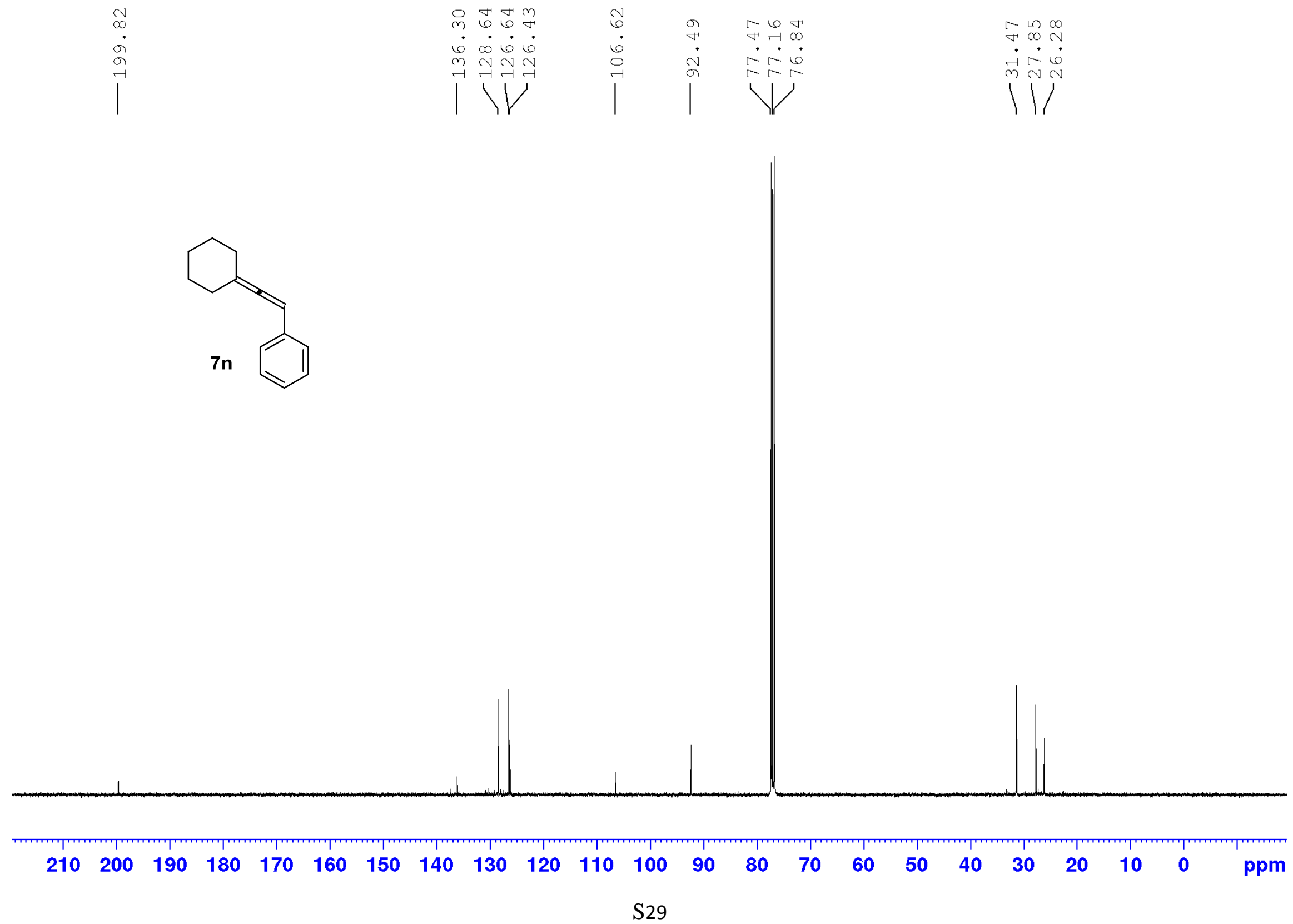

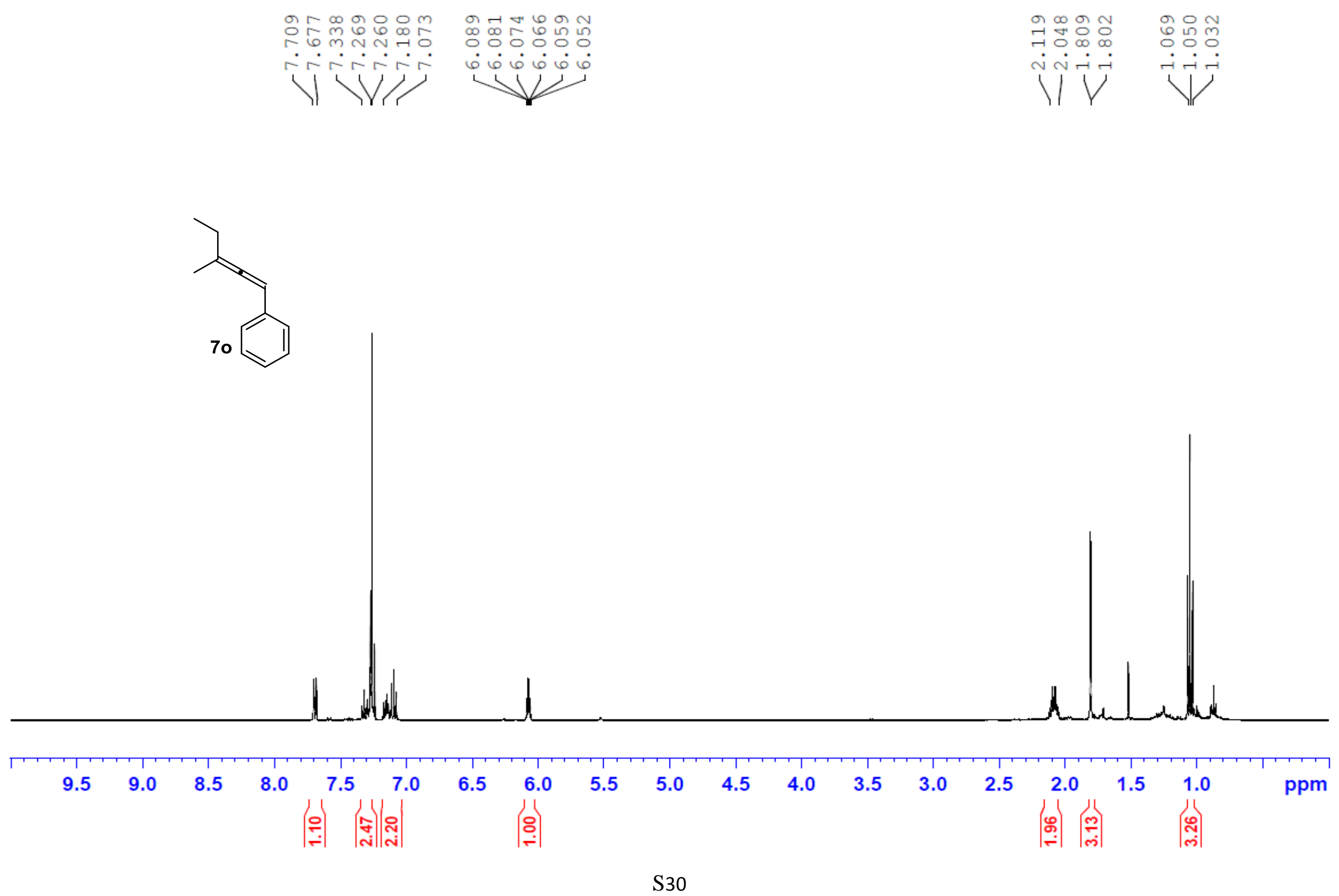


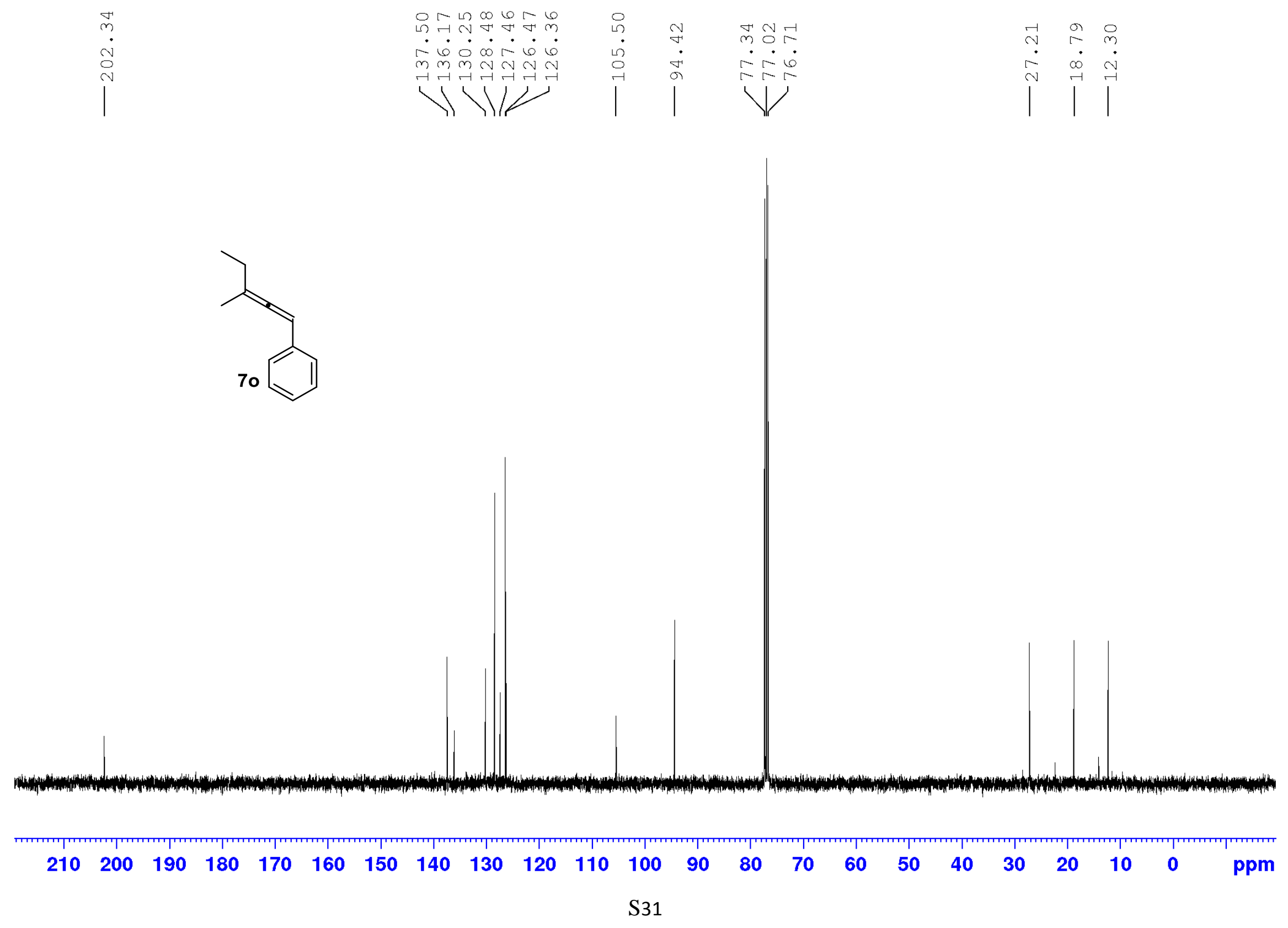

